\title{
LA CONCILIACIÓN Y EL PROCEDIMIENTO ABREVIADO, COMO UNA VIOLACIÓN A LOS DERECHOS DE LAS NIÑAS VÍCTIMAS EN LOS DELITOS SEXUALES EN PROCESO DE ADOLESCENTES EN CONFLICTO CON LA LEY PENAL
}

Conciliation and abbreviated procedure, as a violation of the rights of girls victims in sexual offences in the process of adolescents in conflict with criminal law

\section{Dina Josefina Ochoa Escribá}

Doctora en Derecho por la Universidad Mariano Gálvez de Guatemala, Magister en Derecho de las Mujeres, Género y Acceso a la Justicia, Universidad de San Carlos de Guatemala, Licenciada en Ciencias Jurídicas y Sociales, Abogada y Notaria, Universidad Mariano Gálvez de Guatemala, Jueza de los Juzgados especializados contra el Femicidio y otras formas de violencia contra la mujer.

Magistrada Presidenta de la Corte de Constitucionalidad 2018-2019.

dinaochoa2002@yahoo.com

https://doi.org/10.37346/opusmagna.v16i01.4 


\section{Resumen}

El problema que presenta la conciliación y el procedimiento abreviado al resolver por estos procedimientos situaciones de niñas víctimas de delitos sexuales en un proceso de adolescentes en conflicto con la ley penal, lo cual da como resultado una violación del Estado a derechos fundamentales a la dignidad, integridad y a la libertad. La investigación conlleva en evidenciar la improcedencia de aplicar estas instituciones jurídicas ya que se violenta la Convención para la Eliminación de todas las Formas de Discriminación contra la Mujer -CEDAW-Convención Interamericana para Prevenir, Sancionar y Erradicar la Violencia contra la Mujer-BELÉM DO PARÁla Convención sobre los derechos del niño y lo establecido en el Art. 185 del Decreto número 27-2003.

Palabras clave: Derechos humanos, Derecho Procesal Penal, justicia especializada, derechos de las niñas, violencia sexual, víctima, victimización.

\section{Abstract}

The problem of conciliation and abbreviated procedure in resolving by these proceedings situations of girls who are victims of sexual offences in a trial of adolescents in conflict with criminal law, resulting in a violation of the State to fundamental rights to dignity, integrity and freedom. The research involves evidence of the inappropriateness of applying these legal institutions as the Convention on the Elimination of All Forms of Discrimination against Women - CEDAW-Inter-American Convention to Prevent, Punish and Eradicate Violence against WomenBELEEM DO PARÁ- The Convention on the Rights of the Child and the provisions of Article 185 of Decree No. 27-2003.

Key words: Human Rights, Criminal Procedural Law, Specialized Justice, Girls' Rights, Sexual Violence, victim, victimization. 


\section{SUMARIO}

Introducción a la segunda parte

3. Consecuencias jurídicas de las sanciones

3.1 Medidas de coerción

3.1.1. La obligación del adolescente de presentarse periódicamente ante el juez

3.1.2. La obligación de someterse al cuidado de una persona adulta e idónea

3.1.3. Arresto domiciliario

3.1.4. La privación de libertad provisional

3.1.5. Criterio de oportunidad reglado

3.2. Suspensión condicional de la sanción de privación de libertad

3.3. Otras formas anormales de terminar el proceso

\subsubsection{Sobreseimiento}

3.3.2. Falta de mérito

3.4. Las Sanciones socioeducativas o sanciones penales juveniles

3.5. Libertad asistida

3.6. Prestación de servicios a la comunidad

3.7. Reparación de los daños al ofendido

3.8. Órdenes de orientación y supervisión

3.9. Instalarse en un lugar de residencia determinado o cambiarse de él

3.10. Abandonar el trato con determinadas personas

3.11. Eliminar la visita a centros de diversión determinados

3.12. Obligación de matricularse en un centro de educación formal o en otro cuyo objetivo sea enseñarle alguna profesión u oficio

3.13. Abstenerse de ingerir bebidas alcohólicas, substancias alucinógenas, enervantes, estupefacientes o tóxicas que produzca adicción o hábito

3.14. Obligación de someterse a programas de tipo formativo, cultural, educativo, profesional, laboral, de educación sexual, educación vial u otros similares

3.15. Ordenar el internamiento terapéutico del niño, niña o adolescente o el tratamiento ambulatorio en un centro especializado de salud, público o privado, para desintoxicarlos o eliminar su adicción a las drogas antes mencionadas

3.16. Privación del permiso de conducir

3.17. Sanciones privativas de libertad

3.18. Privación de libertad domiciliaria

3.19. Privación de libertad durante el tiempo libre

3.20. Privación de libertad en centros especializados durante fines de semana, comprendido desde el sábado, de las ocho horas, hasta el domingo a las dieciocho horas

3.21. Privación de libertad en centros especializados de cumplimiento en régimen abierto, semiabierto o cerrado

3.21.1. Régimen abierto

3.21.2. Régimen semiabierto

3.21.3. Régimen cerrado

4. Violación a los derechos de las niñas víctimas, respecto a la aplicabilidad de la conciliación en el procedimiento abreviado

4.1. Concepto de víctima 
4.1.2. Concepto de niña víctima

4.2. Grados de victimización

4.2.1. Victimización primaria sobre los niños, niñas y adolescentes

4.2.2. Victimización secundaria sobre las niñas, niños y adolescentes

4.2.3. Victimización terciaria

4.3. Consecuencias del delito de violación en la niña

4.3.1. Problemas emocionales

4.3.2. Problemas de relación

4.3.3. Problemas de conducta y adaptación social

4.3.4. Problemas funcionales

4.3.5. Problemas sexuales

4.3.6. Embarazo

4.3.7. Transmisión intergeneracional

4.4. Derechos de las niñas víctimas

4.4.1. Derecho a la dignidad

4.4.2. Derecho a la justicia

4.4.3. Derechos procesales

4.4.4. Derecho de reparación del daño

4.4.5. Derecho a la devolución de los bienes involucrados en el Proceso penal

4.4.6. Derecho a la asistencia médica

4.4.7. Derecho a la atención y asistencia victimológica especializada Por las oficinas de atención a la víctima

4.5. Análisis de casos relacionados con niñas víctimas del delito de violación

4.5.1. Violación sexual

4.6. Casos específicos

4.6.1. Causa 01065-2015-20027 a cargo del juzgado segundo de adolescentes en conflicto con la Ley Penal del departamento de Guatemala, por el delito de agresión sexual

4.6.2. Causa 01065-2015-00027 a cargo del juzgado segundo de adolescentes en conflicto con la Ley Penal del departamento de Guatemala, por el delito de agresión sexual

4.6.3. Causa 01065-2016-0050 a cargo del juzgado segundo de adolescentes en conflicto con la Ley Penal del departamento de Guatemala, por el delito de violación

4.6.4. Causa 01065-2015-0041 a cargo del juzgado segundo de adolescentes en conflicto con la Ley Penal del departamento de Guatemala, por el delito de agresión sexual, en audiencia de procedimiento abreviado.

\section{Conclusiones}

Bibliografia 


\section{INTRODUCCIÓN A LA SEGUNDA PARTE}

Como un aporte especial en esta edición del Opus Magna 2020 se presenta la segunda parte de la obra: "La Conciliación y el Procedimiento Abreviado, como una violación a los derechos de las niñas víctimas en los delitos sexuales en proceso de adolescentes en conflicto con la ley penal" para que se concluya el propósito de ser una herramienta no solo de lectura sino de análisis, critica y reflexión para ahondar en los derechos humanos de las niñas y cómo determinados procedimientos procesales, como lo es el Procedimiento Abreviado, al resolver en casos de niñas víctimas de delitos sexuales dentro de un proceso de adolescentes en conflicto con la ley penal, resulta improcedente su aplicación; ya que es inadmisible frente al marco convencional tanto universal como específicamente en la Convención para la Eliminación de todas las Formas de Discriminación contra la Mujer -CEDAW-, la Convención Interamericana para Prevenir, Sancionar y Erradicar la Violencia contra la Mujer -Belém Do Pará- y la Convención sobre los Derechos del Niño, y en el orden interno lo establecido en el Artículo 185 del Decreto número 27-2003, Ley de Protección Integral de la Niñez y Adolescencia.

Esta publicación contiene los capítulos tercero y cuarto de la tesis para optar a grado académico de magister en Derecho de las Mujeres, Género y Acceso a la Justicia en la Facultad de Ciencias Jurídicas y Sociales de la Universidad de San Carlos de Guatemala, que fue publicada en el año $2018^{1}$.

$1 \quad$ N. del E. Por ser una obra de carácter académico refrendada por la Universidad de San Carlos de Guatemala, esta publicación no fue sometida al Consejo Editor. Agradecemos la generosidad de la Dra. Dina Josefina Ochoa Escribá al compartir su trabajo de tesis de maestría en el Opus Magna Constitucional. 


\section{CAPÍTULO III}

\section{Consecuencias jurídicas de las sanciones}

\subsection{Medidas de coerción}

La medida de coerción es la primera consecuencia jurídica del proceso penal de adolescentes en conflicto con la ley penal, como ya lo mencioné en el capítulo anterior. Es un medio de restricción al ejercicio de derechos personales o patrimoniales del adolescente sujeto a un proceso penal, que se utiliza con el objetivo de asegurar y garantizar la presencia del adolescente en el proceso, asegurar las pruebas, proteger a la víctima, al denunciante o testigos. La ley de Protección Integral de la Niñez y la Adolescencia en su artículo 180 enumera varias medidas de coerción, otorgándoles así al juez las herramientas adecuadas para prevenir el peligro de fuga y de obstaculización de la investigación, el momento adecuado para aplicarlas es en la primera declaración del adolescente, luego de haberse dictado auto de procesamiento, el juez debe valorar si es necesaria o no imponerla. El espíritu de la ley tiene como principio que la medida de coerción de privación de libertad condicional debe aplicarse como último recurso, debiendo buscarse aplicar medidas cautelares menos gravosas, que sean adecuadas razonablemente para prevenir el peligro de fuga y de obstaculización. Es aquí donde la Defensa Pública Penal debe velar porque este principio se cumpla, utilizando los recursos adecuados para cuidar que, si la medida es muy severa, se apele la resolución que la imponga. Tomando como base el principio de protección integral y de proporcionalidad, la imposición de la medida cautelar debe tener proporción con el hecho del cual se acusa al adolescente (Godínez López, D.A, (2005). La aplicación del proceso de adolescentes en conflicto con la ley penal y sus consecuencias jurídicas y sociales en Guatemala (Tesis de Licenciatura en Ciencias Jurídicas y Sociales. Universidad de San Carlos de Guatemala).

Estas medidas no deben durar más de dos meses, pero este plazo se puede prorrogar por dos meses más a excepción de la privación de libertad provisional. No obstante, las medidas de coerción que más se aplican son las siguientes: 
a. La obligación del adolescente de presentarse periódicamente ante el juez.

b. La obligación de someterse al cuidado de una persona adulta e idónea.

c. Arresto domiciliario.

d. Privación de libertad provisional.

\subsubsection{La obligación del adolescente de presentarse periódicamente ante el juez}

Es una medida de coerción que consiste en asegurar que el adolescente no desaparezca durante el desarrollo del proceso, debiéndose presentar al juzgado a firmar un libro de control que está a cargo del secretario, y los que gozan de estas medidas en su mayoría han sido por hechos referentes a robo agravado, robo, entre otros delitos menores.

\subsubsection{La obligación de someterse al cuidado de una persona adulta e idónea}

Es una medida de coerción que consiste en poner al adolescente bajo cuidado de un adulto, el cual generalmente es el padre o la madre, en caso de no tenerlos, los familiares más cercanos. Este adulto es el responsable de su cuidado y custodia, debe asegurarse de que el adolecente no desaparezca durante el desarrollo del proceso y presentarlo ante el juez e informar de su situación cuantas veces sea solicitado. El adulto debe ser idóneo, quiere decir que en caso de que los padres no sean los adecuados para cumplir con la medida se puede nombrar a otra persona.

\subsubsection{Arresto domiciliario}

Es una medida de coerción de consiste en restringir la libertad de locomoción al adolescente, pero no totalmente, en su propia residencia $\mathrm{u}$ otra idónea que el juez señale, bajo la responsabilidad de una persona adulta, garantizando que en ninguna forma esta medida perjudique su horario de estudios o su horario laboral, esta disposición hace que sea una medida muy 
difícil de controlar, además de no contar con el elemento humano necesario para controlar el cumplimiento de la misma.

\subsubsection{La privación de libertad provisional}

Es una medida de coerción de carácter excepcional y muy controversial. Consiste en la restricción de libertad de locomoción del adolescente, y se encuentra regulada en el artículo 182 de la Ley de Protección Integral de la Niñez y Adolescencia.

Cabe mencionar que, durante la vigencia de la doctrina de situación irregular, la detención provisional adquiría el carácter de una respuesta inmediata a la situación de "peligro social" en que estaría el adolescente, para alejarlo del medio social en el cual se desenvolvía cuando estimara que este era inconveniente. Para la doctrina de situación irregular no tenía importancia la presunción de inocencia, de modo que esta garantía no podía actuar como límite para el dictado de la privación de libertad provisional, siendo suficiente la existencia de la situación de riesgo social.

El principio educativo establece que la privación de libertad condicional debe ser evitada al máximo para los efectos negativos que produce en los adolescentes, únicamente se impondrá como último recurso, y en ese caso debe durar el plazo más breve posible. Debe efectuarse en forma separada de la prisión preventiva de los adultos. La regla 13.4 de las Reglas Mínimas de las Naciones Unidas para la administración de justicia de menores establece: "Los menores que se encuentren en prisión preventiva estarán todos separados de los adultos y recluidos en establecimientos distintos o en recintos separados en establecimientos en que haya detenidos adultos"; y en el numeral 13.5 establece: "Mientras se encuentren bajo custodia, los menores recibirán cuidados, protección y toda asistencia social educacional, profesional, psicológica, médica y física que requieran habida cuenta de su edad, sexo y características individuales".

Al igual que en el Derecho Procesal de Adultos, para poder imponer esta medida, se debe tener la sospecha suficiente de culpabilidad del adolescente, es esto una consecuencia del principio de proporcionalidad, ya que no puede 
exigirse a un adolescente que sufra una privación de libertad, cuando no existe suficiente grado de probabilidad como para esperar que pueda dictarse posteriormente una sentencia condenatoria, y más en este tipo de proceso, por el carácter especial de su materia.

Además de la sospecha suficiente de culpabilidad del adolescente, debe existir una de las causales para imponerla, las cuales según el artículo 182 de la Ley de Protección Integral de la Niñez y Adolescencia son:

a. Que exista peligro de fuga y/o de obstaculizar la averiguación de la verdad; $y$

b. Que el hecho que se atribuya al adolescente sea constitutivo de un delito que implique grave violencia y sea contra la vida, la integridad física, la libertad individual o sexual de las personas.

Además de lo anterior, es aquí muy importante aplicar el principio de proporcionalidad, entre lo que implica la medida para adolescente y la gravedad de los hechos atribuidos, es entonces importante establecer que la medida de privación de libertad provisional deba ser necesaria, idónea y proporcional en sentido estricto, esto exige que se lleve a cabo un balance de intereses para determinar si el sacrificio de los intereses individuales que representa la medida, guarda relación proporcionada con la importancia del interés estatal que trata de salvaguardar. Además, debe tomarse en cuenta que no es posible determinar la privación de libertad condicional de un adolecente cuando, en caso de dictarse una sentencia condenatoria, no puede disponerse en internamiento provisional. (Godínez López, D.A.(2005). La aplicación del proceso de adolescentes en conflicto con la ley penal y sus consecuencias jurídicas y sociales en Guatemala (Tesis de Licenciatura en Ciencias Jurídicas y Sociales. Universidad de San Carlos de Guatemala). En Guatemala existen dos centros de Prisión Provisional, uno para mujeres y otro para varones. Cuentan con el siguiente personal: psicólogo, médico, monitores, trabajador social, maestros y pedagogo. El de mujeres se nomina Centro Juvenil de Detención Provisional Gorriones; el inconveniente es que en el mismo también se encuentran internadas las adolescentes que están cumpliendo con la sanción socioeducativa 
de privación de libertad, el cual tiene a su disposición talleres de costura, pintura y cocina. Las adolescentes internas no se encuentran separadas por edades pues no es muy difícil controlarlas por la cantidad que ahí se encuentra recluida. El centro de prisión provisional para varones se denomina Centro Juvenil de Prisión Provisional (CEJUDEPP), los adolescentes internos no se encuentran separados por edades, esto es un problema serio porque la experiencia nos enseña que generalmente los adolescentes mayores tienden a abusar de los menores, por las noches los adolescentes son separados por dormitorios, tratan de ubicar a los miembros de maras en un solo dormitorio. Un problema serio lo constituye el que el centro no cuenta con las instalaciones necesarias, ni con programas educativos como talleres para mantener ocupados a los adolescentes, así que se las ingenian organizando torneos deportivos y otras actividades. La falta de presupuesto es la justificación a esta problemática.

\subsubsection{Criterio de oportunidad reglado}

El criterio de oportunidad reglado trata de establecer reglas claras para prescindir de la acusación penal frente a casos específicos. Es una excepción al principio de obligatoriedad del ejercicio de la acción penal con la que tradicionalmente ha funcionado la justicia penal de adultos. No se trata de autorizar al Ministerio Público para transar a su antojo con la otra parte, sino de reconocer superiores intereses jurídicos que hacen innecesaria iniciación del proceso y la eventual pena, aplicando así el principio de intervención mínima del Estado, en otras palabras, el Ministerio Público solicita permiso para no investigar. La ley no es muy clara con respecto a los requisitos que se necesitan para poder aplicar el criterio de oportunidad reglado, solo establece que se puede aplicar cuando se trate de un hecho que por su insignificancia o lo exiguo de la participación del adolescente en el hecho no afecte el interés público, se podrá pedir al juez que se prescinda total o parcialmente de la persecución, la limite a una o varias infracciones o a alguna de las personas que han participado en el hecho. Es, pues, el Ministerio Público como ente encargado de la persecución penal, el encargado de aplicar el principio de proporcionalidad durante la fase de investigación, analizando en qué casos es necesario iniciar la persecución penal. El criterio de oportunidad reglado ofrece la oportunidad de aplicar los principios de la justicia penal juvenil, tomando en cuenta que para los 
adolescentes la intervención del aparato coercitivo solamente producirá efectos negativos.

Como característica especial, el criterio de oportunidad reglado puede volverse a otorgar a un adolescente que ya haya gozado de este beneficio, es un mecanismo desjudicializador muy efectivo por el cual el proceso termina en forma anticipada. El juez al otorgarlo advierte al adolescente que es un beneficio el que le está otorgando invitándolo a no cometer más hechos delictivos y ofreciéndole una oportunidad para continuar con su vida sin infringir la ley. Durante los meses de enero y febrero del año 2005 el juez Segundo de Adolescentes en Conflicto con la Ley Penal otorgó el beneficio del criterio de oportunidad a 31 adolescentes, los que estaban sindicados de cometer los hechos delictivos de portación ilegal de arma de fuego, hurto, portación ilegal de explosivos, robo agravado en concurso con lesiones, uso de documentos falsos, robo, comercio tráfico y almacenamiento ilícito de drogas, atentado, portación ilegal de armas blancas y extorsión, en algunos casos en concurso con otros delitos.

Una desventaja del criterio de oportunidad reglado es que, al aplicarlo, se pierde la oportunidad de integrar al adolescente a un programa de rehabilitación, pues al otorgarlo se desliga totalmente al adolescente del proceso. Es contradictorio pues, que a adolescentes que cometan un delito menos grave o una falta lo sentencian remitiéndolos a programas como prestación de servicios a la comunidad y a los adolescentes que se les otorga el beneficio del criterio de oportunidad reglado no se les incluya en ningún programa, a pesar de que el hecho que se les atribuye es más grave. Esto favorece la reincidencia en los adolescentes a los que se les aplique este beneficio.

\subsection{Suspensión condicional de la sanción de privación de libertad}

Consiste en la interrupción o cesación de una sanción socioeducativa privativa de libertad. Es un beneficio que el juez puede otorgar al adolescente al momento de dictarse el fallo o en los casos en que exista sentencia que haya pasado por autoridad de cosa juzgada. Se suspende la sanción socioeducativa privativa de libertad por un periodo igual al doble de la sanción impuesta, siempre y cuando existan los siguientes presupuestos: 
a. Los esfuerzos del adolescente por reparar el daño causado.

b. La falta de gravedad de los hechos cometidos.

c. La conveniencia para el desarrollo educativo o laboral del adolescente.

d. La situación familiar y social en que se desenvuelve.

e. El hecho de que el adolescente haya podido constituir, independientemente, un proyecto de vida alternativo.

Si el adolescente durante el tiempo que dure la suspensión condicional de la sanción privativa de libertad comete un nuevo hecho que constituya violación a la ley penal, se le revocará este beneficio y cumplirá la sanción impuesta.

\subsection{Otras formas anormales de terminar el proceso}

El artículo 203 de la Ley de Protección Integral de la Niñez y la Adolescencia regula: "Agotada la averiguación o concluido el plazo para la misma, el Ministerio Público solicitará al juez, en forma breve y razonada según el caso: a) El sobreseimiento, clausura provisional o el archivo. (...) d) Aplicación del procedimiento abreviado". Figuras clásicas del procedimiento común, es por ellos que facultados por el artículo 141 de la ley se utiliza supletoriamente lo regulado por el Código Procesal Penal respecto a estas figuras.

\subsubsection{Sobreseimiento}

Es una forma anormal de terminar el proceso, que no es otra cosa que el sobreseimiento provisional. Se utiliza con el objeto de no dejar ningún tipo de casos sin ninguna resolución, pues al exigir la ley la certeza de la inocencia para sobreseer y la posibilidad de condena para acusar, quedan entre ambas una enorme cantidad de casos que no permiten arribar al fundamento de una u otra decisión. La realidad indica que los procedimientos terminan en estos casos de manera irregular con un archivo de hecho sin decisión alguna, lo que no debe ser. La clausura permite que en el plazo limitado por la prescripción se pueda completar la información y formular el requerimiento que procede. Este plazo es de 5 años, según lo establece el artículo 345 Quater del Código Procesal Penal en su inciso 2. Mientras no concurra este plazo, si surgieren nuevos elementos 
de prueba que tornen viable la reanudación de la persecución penal para arribar a la apertura del juicio o al sobreseimiento, el juez, a pedido del Ministerio Público o de otra de las partes, permitirá la reanudación de la investigación. Esta figura pues, no desliga totalmente al adolescente del proceso, siempre y cuando no haya transcurrido el término de la prescripción.

Nuevamente se presenta la desventaja de aplicar la clausura provisional porque al aplicarlo se pierde la oportunidad de integrar al adolescente a un programa de rehabilitación, pues al otorgarlo se desliga totalmente al adolescente del proceso, sucede lo mismo que explique al aplicar el criterio de oportunidad reglado, pero se puede reabrir el proceso si se cuanta con los elementos necesarios.

\subsubsection{Falta de mérito}

Es otra forma anormal de terminar el proceso que se utiliza cuando no concurren los presupuestos para dictar auto de prisión preventiva regulados en el artículo 13 de nuestra Constitución Política de la República, en otras palabras, es una abstención del ejercicio de la acción penal por parte del Ministerio Público que se aplica cuando no existe información o medios de convicción suficientes que hagan creer que se ha cometido un delito, y no concurran motivos racionales suficientes para creer que la persona detenida lo ha cometido o participado en él. En los meses de enero y febrero del año 2005 el juez Segundo de Adolescentes en Conflicto con la Ley Penal otorgó la Falta de Mérito a 13 adolescentes, los que estaban sindicados por los hechos delictivos de robo agravado, robo, tenencia de armas de fuego, comercio, tráfico y almacenamiento ilícito.

\subsection{La sanciones socioeducativas o sanciones penales juveniles}

Como sabemos, los adolescentes son inimputables, esto es que no se le puede imputar un hecho delictivo de la misma forma que se hace con un adulto; en Guatemala antes de la vigencia de la Ley de Protección Integral de la Niñez y la Adolescencia, cuando un adolescente cometía un delito, lo dejaban libre por su inimputabilidad, o era sometido a un proceso en el cual no se respetaba 
la mayoría de sus garantías, sancionándolo de forma inmoderada, lesionando su persona y su autoestima. Pero es el caso que de esta forma lo único que se lograba era estimular al adolescente a seguir cometiendo delitos, sabiendo bien que nunca estarían sujetos a un proceso penal o al internarlos en un centro de adolescentes sin las condiciones adecuadas lo único que se ha logrado es iniciar la carrera delincuencial de estos adolescentes. Pero también se debe reconocer que el comportamiento de los jóvenes que no se ajusta a los valores o normas generales de la sociedad es con frecuencia parte del proceso de madurez y tiende a desaparecer en la mayoría de personas, y también que el hecho de que califiquemos o encasillemos a los adolescentes como pre delincuentes, a menudo solo logra reforzar la conducta indeseable en ellos.

Si bien esta es una norma general, se considera que en los casos donde los jóvenes cometen un delito sexual debe atenderse de manera diferenciada y aplicar penas de acuerdo al delito, reconociendo que con ello también se está dañando los derechos de las niñas víctimas.

La Justicia de Menores se debe concebir como una parte muy importante del desarrollo de cada país, y debe administrarse en un marco de justicia social para todos los menores, de manera que contribuya a la protección de los jóvenes y al mantenimiento del orden pacífico de la sociedad. Y es por medio de las sanciones socioeducativas que se trata de rehabilitar al adolescente infractor de la ley penal, aplicando una sanción proporcional a las circunstancias y a la gravedad del delito, y proporcional a las circunstancias y necesidades del menor, como también proporcional a las circunstancias y necesidades de la sociedad. Cualquier sanción socioeducativa aplicada debe tener una finalidad primordialmente educativa, tomando en cuenta que el adolescente es parte de un grupo social diferenciado al que se le debe respetar su propia identidad como grupo y como personas en una etapa especial de su desarrollo y socialización.

La existencia de un marco jurídico claro como lo es la Ley de Protección Integral de la Niñez y la Adolescencia busca la prevención general de los delitos, la prevención general de sanciones arbitrarias o desproporcionadas frente a los adolescentes transgresores de la ley penal, y lo más importante, promover en el adolescente transgresor un sentimiento de responsabilidad por sus actos y de respeto por los derechos de terceros. En esta normativa también prevalece el 
fin de prevención especial sobre el de prevención general, pues no se pretende imponer sanciones que generen intimidación en los demás miembros de la sociedad, lo que sería imposible por el carácter reservado y confidencial del procedimiento penal donde nadie se entera del tipo de sanción impuesta, se persigue pues la reinserción del adolescente en su familia y comunidad a través de su educación integral, cuidando que en ningún caso la sanción que se imponga sea desproporcionada al hecho o circunstancias personales, familiares y sociales del adolescente, lo que sí puede hacerse es justificar con ese fin una sanción menor a la que proporcionalmente corresponde.

Las sanciones socioeducativas son las consecuencias jurídicas que se aplican a los adolescentes que han cometido un hecho delictivo cuyo objetivo es reinsertar al adolescente en su familia y sociedad, promoviendo por medio de estas medidas la formación de ciudadanos responsables, fortaleciendo los valores positivos como el sentimiento de responsabilidad por los propios actos y el respeto de los derechos de terceros. Persigue responsabilizar al adolescente por sus actos y su orientación hacia la adquisición de responsabilidades que le plantea la vida adulta, algunas de las cuales son parte de su vida diaria.

La Ley de Protección Integral de la Niñez y Adolescencia clasifica a las sanciones socioeducativas de la siguiente forma:

i. Sanciones socioeducativas:

a. Amonestación y advertencia.

b. Libertad asistida.

c. Prestación de servicios a la comunidad.

d. Reparación de los daños al ofendido.

ii. Órdenes de orientación y supervisión:

a. Instalarse en un lugar de residencia determinado o cambiarse de él.

b. Abandonar el trato con determinadas personas.

c. Eliminar la visita a centros de diversión determinados.

d. Obligación de matricularse en un centro de educación formal o en otro cuyo objetivo sea enseñarle alguna profesión u oficio.

e. Abstenerse de ingerir bebidas alcohólicas, substancias alucinógenas, enervantes, estupefacientes o tóxicas que produzcan adicción o hábito. 
f. Obligación de someterse a programas de tipo formativo, cultural, educativo, profesional, laboral, de educación sexual, de educación vial y otros similares.

iii. Ordenar el internamiento terapéutico del niño, niña o adolescente, o el tratamiento ambulatorio en un centro especializado de salud, público o privado, para desintoxicar o eliminar su adicción a las drogas antes mencionadas.

iv. Privación del permiso de conducir.

v. Sanciones privativas de libertad:

a. Privación de libertad domiciliaria.

b. Privación de libertad durante el tiempo libre.

c. Privación de libertad en centros especializados durante fines de semana, comprendidos desde el sábado, de las ocho horas, hasta el domingo a las dieciocho horas.

d. Privación de libertad en centros especializados de cumplimiento en régimen abierto, semiabierto o cerrado.

Las mencionadas son las sanciones socioeducativas que regula la Ley de Protección Integral de la Niñez y la Adolescencia en su artículo 238, las que estudiaremos una a una. Considero que es importante mencionar que según el artículo 239 de esta misma ley, para determinar la sanción a aplicarse se debe tener en cuenta:

a. La comprobación de una conducta que viole la ley penal.

b. La comprobación de que el adolescente ha realizado o participado en la trasgresión a la ley penal.

c. La capacidad para cumplir la sanción, asimismo, la proporcionalidad, racionalidad e idoneidad de esta.

d. La edad del adolescente, sexo, origen cultura y sus circunstancias personales, familiares y sociales.

e. Los esfuerzos del adolescente por reparar los daños.

d. Los efectos de la sanción para la vida futura del adolescente. 


\subsubsection{Amonestación y advertencia}

Es una sanción socioeducativa de ejecución instantánea y tiene como objetivo llamar la atención del adolescente exhortándolo para que en lo sucesivo se acoja a las normas de trato familiar y convivencia social. La amonestación versará sobre la conducta delictiva realizada y el juez dice al joven que debe procurar una vida sin la comisión de delitos. Este tipo de sanción es utilizada por el juez de paz. Este en forma oral y de forma clara y directa hará comprender al adolescente sobre la gravedad del hecho cometido y las consecuencias que ha tenido o podría haber tenido tanto para él como para terceros, exhortándolo a no volver a cometer tales hechos en el futuro. En la misma audiencia el juez podrá, de considerarlo prudente, recordar a los padres, tutores o encargados sus deberes en la formación, educación y supervisión del adolescente. Este tipo de sanción es aplicada en faltas y delitos de poca trascendencia, es controlada específicamente solo por los jueces de paz.

\subsection{Libertad asistida}

La sanción socioeducativa socializadora e individualizada ejecutada en libertad bajo asistencia y supervisión de personal especializado, está orientada a la adquisición de habilidades, capacidades y aptitudes para el desarrollo social y personal del adolescente. Consiste en otorgar la libertad al adolescente sancionado bajo el control del Juzgado de Control de Ejecución de Sanciones, quedando sometido a los programas de orientación o de cualquier otro tipo que se consideren necesarios, según se haya establecido en el Plan Individual de Libertad Asistida que deberá elaborar el equipo técnico de la Secretaría de Bienestar Social, a cuyo cargo se encuentra el Programa que ejecuta la medida. Debe iniciarse su cumplimiento 15 días después de haber sido ordenada, plazo durante el cual el equipo técnico responsable elaborará su plan individual de libertad asistida. Este equipo técnico está integrado por un psicólogo y una trabajadora social, ambos son miembros del Programa de Libertad Asistida que existe desde el año 2000 en la Secretaría de Bienestar Social de la Presidencia de la República. Su duración no debe ser mayor a 2 años. Es uno de los pocos programas que existe bien organizado en la Secretaría de Bienestar Social, y que intenta favorecer una mejor integración del adolescente a la comunidad. 
Esta sanción socioeducativa procede en los supuestos de "delitos graves", incluso en aquellos donde concurra violencia grave contra la integridad física, la libertad individual o libertad y seguridad sexual de las personas, siempre que las condiciones concretas del caso y el Interés superior del niño así lo aconsejen. Los momentos en los que se impone son en la resolución final o sentencia, como medida definitiva, al revisarse otra medida impuesta, y en apelación al resolverse el recurso. El equipo técnico deberá presentar el plan individualizado al juez, para que este lo apruebe, si no estuviese conforme con el mismo, lo podrá modificar pudiendo consultar al equipo técnico para luego aprobarlo. Para poder elaborar el plan, el equipo técnico debe realizar las visitas necesarias al domicilio del adolescente y lugares que se consideren necesarios para establecer cuál es el entorno social donde se desenvuelve y así establecer adecuadamente las áreas a trabajar. Las áreas pueden ser:

a. Familiar: se fomenta y fortalecen los vínculos familiares del adolescente por medio de terapias grupales o individuales.

b. Laboral: la encargada del programa coordina que el adolescente continúe trabajando y si no trabaja, por medio del programa se ha logrado ubicar a varios adolescentes en un puesto de trabajo; las empresas privadas que colaboran con contratar a estos adolescentes son: Caligráfic (imprenta) y Colorin (fábrica de pinturas), varios adolescentes trabajan con familiares.

c. Educativa: esta es una de las áreas prioritarias del programa, pues cumplirá con la función de reducir los niveles de atraso escolar en los adolescentes que lo necesiten y velará por el rendimiento escolar de quienes se encuentran estudiando al momento de la imposición de la medida, gestionando becas con la Asociación de Prevención del Delito (APREDE), que cuenta con cursos de computación, cursos de panadería y primaria acelerada. En la actualidad, hay 8 adolescentes utilizando este servicio, los demás ya estudian o trabajan por su cuenta.

d. Desintoxicación: no hay antecedentes de internamiento de algún adolescente sometido a esta medida socioeducativa, pero es parte de las funciones de los encargados del programa coordinar el internamiento del adolescente que presente algún tipo de adicción. 
El plan individual debe contener los datos generales del adolescente, antecedentes delictivos del mismo, nombres de las personas con quien vive, se establecen los objetivos generales y específicos, las metas a corto y largo plazo dependiendo del tiempo que dure la medida, se establece un programa de actividades fijando fechas para las terapias individuales por lo menos una vez a la semana, y terapias grupales cada 15 días, para establecer todo esto se debe tener en cuenta con base en el principio de protección integral, las condiciones del adolescente y tomar muy en cuenta sus necesidades antes que las necesidades del programa.

Una vez iniciada la ejecución de la medida, el programa debe enviar al juez de Adolescentes en Conflicto con la Ley Penal informes bimensuales sobre los avances del adolescente, y cada tres meses acudir a las audiencias de revisión de la medida que la ley establece ante la juez de Ejecución y Control de Medidas. Una de sus características especiales es que la libertad asistida no procederá en caso de que el adolescente sea reincidente en la comisión de un hecho de igual o mayor gravedad a otro anterior en que se le impuso la medida de libertad asistida, salvo que, atendiendo a las circunstancias del caso y el interés superior del adolescente, el juez estime oportuno volverla a aplicar.

\subsection{Prestación de servicios a la comunidad}

Esta sanción socioeducativa consiste en que el adolescente en forma gratuita, para compensar el daño ocasionado, presta sus servicios a entidades públicas o privadas como hospitales, escuelas, parques nacionales, estaciones de bomberos; encontrándose en libertad y bajo la supervisión de un equipo multidisciplinario, que persigue responsabilizar a los adolescentes a través de la prestación de un servicio social constructivo y no remunerado a su comunidad.

El cumplimiento de esta sanción socioeducativa debe iniciarse 15 días después de haber sido ordenada, plazo durante el cual el equipo técnico responsable elaborará el plan individual. Este equipo técnico está integrado por un psicólogo y una trabajadora social, ambos son miembros del Programa de Prestación de Servicios a la Comunidad que existe desde enero del año 2004 a cargo de la Secretaría de Bienestar Social de la Presidencia de la República. Su duración no debe ser mayor a seis meses, en caso fuera impuesta por el juez de 
Adolescentes en Conflicto con la Ley Penal; y de dos meses cuando la impone un juez de paz. Es otro de los pocos programas que existe bien organizado en la Secretaría de Bienestar Social.

Esta sanción socioeducativa procede en los supuestos de faltas o delitos no muy graves. El equipo técnico deberá presentar el plan individualizado al juez, para que este lo apruebe, si no estuviese conforme con el mismo, lo podrá modificar pudiendo consultar al equipo técnico para luego aprobarlo. Para poder elaborar el plan el equipo técnico debe realizar las visitas necesarias al domicilio del adolescente y lugares que se consideren necesarios para establecer cuál es el entorno social donde se desenvuelve y así establecer adecuadamente las áreas a trabajar. Las áreas pueden ser:

a. Familiar: se orienta el fortalecimiento de los vínculos familiares del adolescente, por medio de atención y seguimiento del equipo multidisciplinario.

b. Laboral: se atiende aquellos casos en que el adolescente se ausenta de su lugar de trabajo debido al proceso, acudiendo a su centro de trabajo para coordinar que no sea despedido.

c. Educativa: se brinda atención y seguimiento a todos los casos que manifiestan interés por iniciar o continuar sus estudios. Se coordina con instituciones como la Asociación de Prevención del Delito (APREDE), la Dirección General de Educación Extraescolar (DIGEE) y el Instituto Guatemalteco de Educación Radiofónica (IGER).

d. Orientación espiritual: el adolescente a través de la orientación espiritual, toma y retoma sus valores espirituales en la religión que elija, pertenezca o practique, por lo tanto, los encargados del programa coordinan que el adolescente se comunique con su guía espiritual o le buscan uno.

e. Trabajo individual y grupal con el adolescente y su familia y/o responsable: se trabaja cada 15 días con las familias y/o encargados de los adolescentes, en cuanto a la orientación, comprensión y apoyo para el logro de la reinserción del adolescente. 
f. Creación de redes institucionales para la prestación del servicio comunitario: el equipo multidisciplinario identifica y coordina con diversas instituciones sociales a nivel local, regional y nacional para que los adolescentes sujetos al programa cumplan con el servicio comunitario impuesto.

Según el principio de interés superior del adolescente, para determinar qué tipo de servicio y el lugar donde se debe cumplir, se toma en cuenta la capacidad y preparación del adolescente, dándole importancia a lo que puede y quiere hacer, determinando según las condiciones del adolescente el horario bajo el cual debe cumplir la sanción, teniendo cuidado que este no interfiera con su educación y trabajo.

Una vez aprobado el plan el adolescente se presenta ante la coordinadora del programa quien le explica los objetivos del mismo y fija la fecha del inicio de su cumplimiento. La duración del cumplimiento de esta sanción deberá establecerse en jornadas no mayores de 8 horas semanales, pudiendo realizarse lo sábados, domingos o días de feriado sin perjudicar la asistencia a su centro de educación o a su centro de trabajo.

\subsection{Reparación de los daños al ofendido}

Es la sanción socioeducativa que se aplica en la mayoría de los hechos en los que el adolescente lesione bienes materiales; consiste en una obligación de hacer del adolescente a favor de la víctima, con el objeto de resarcir el daño causado o restituir la cosa dañada, esta sanción exige que tanto el adolescente como la víctima estén de acuerdo en este tipo de sanción, ambas partes también pueden acordar sustituir el trabajo por una suma de dinero, en este caso el juez es el encargado de fijar la cuantía.

Cuando el adolescente sea mayor de 15 años, se procurará que el dinero provenga de su esfuerzo propio y que no se provoque un traslado de responsabilidad hacia sus padres, tutores o representantes, será él mismo quien se encargue de resarcir el daño o compensar el perjuicio causado a la víctima. Cuando se trate de un adolescente comprendido entre las edades de 
trece a catorce años, sus padres, tutores o responsables serán solidariamente obligados a responder. Por lo general, son los padres del adolescente los que se asumen la responsabilidad del daño cuando se establece una suma de dinero, y la Certificación de la Sentencia constituye Título Ejecutivo en caso de incumplimiento del pago. Este tipo de sanción es controlada directamente por el juez de paz.

\section{8 Órdenes de orientación y supervisión}

Consisten en mandamientos o prohibiciones que el juez de Adolescentes en Conflicto con la Ley Penal impone para regular la conducta del adolescente y para promover y asegurar su formación. No deben durar más de dos años, y en caso de incumplimiento el juez puede ordenar de oficio o a petición de parte su modificación. El objetivo de las mismas es lograr que el adolescente se aleje del círculo social que influye sobre su comportamiento delictivo, que se abstenga de realizar determinados actos y que se relacione con actividades de proyección social que le distraigan y le permitan ocupar y desarrollar sus habilidades. Su cumplimiento debe iniciar a más tardar un mes después de ser ordenadas, en caso de incumplimiento la ley no regula lo que procede, pero sí establece que el juez de Ejecución puede modificarla dependiendo del informe que le remita el equipo técnico encargado del programa. Pero es precisamente aquí donde existe el problema, pues la Secretaría de Bienestar Social no cuenta con un programa adecuado para este tipo de sanciones socioeducativas, además, es muy difícil poder controlar que se cumplan, se necesitaría crear un programa con suficiente personar para poder cumplirla. Como resultado de mi investigación confirmé que, a la fecha, la Secretaría de Bienestar Social no tiene ningún antecedente de este tipo de sanción.

A continuación detallo cada una de las órdenes de orientación y supervisión que regula la ley.

\subsection{Instalarse en un lugar de residencia determinado o cambiarse de él}

Es una orden de orientación y supervisión que consiste en prohibir al adolescente residir en un lugar determinado, cuando se compruebe que 
el ambiente del lugar en que se desenvuelve resulta perjudicial para su sano desarrollo. El juez de Primera Instancia de Adolescentes o el juez de Ejecución de Sanciones deben establecer el lugar donde el adolescente debe residir o donde estará prohibido. El equipo técnico debe informar al juez sobre las alternativas de residencia del adolescente sancionado, en todo caso se procurará que resida con sus familiares y estos deberán informar al juez sobre la efectividad de esta sanción.

\subsection{Abandonar el trato con determinadas personas}

Es una orden de orientación y supervisión que consiste en ordenarle al adolescente abstenerse a frecuentar personas adultas o jóvenes, las cuales están contribuyendo a que el adolescente lleve una forma de vida delictiva. El juez debe indicar en forma clara y precisa cuáles personas debe el adolescente abandonar en su trato o en su convivencia, durante el tiempo de vigencia de la sanción. Cuando la prohibición de relacionarse con determinada persona se refiera a un miembro del núcleo familiar del adolescente o a cualquier otra persona que resida con él, deberá esta sanción combinarse con la prohibición de residencia.

\subsection{Eliminar la visita a centros de diversión determinados}

Es una orden de orientación y supervisión que consiste en ordenar al adolescente no asistir a ciertos lugares o establecimientos que resulten inconvenientes para su sano desarrollo. El juez de Primera Instancia de Adolescentes deberá indicar en forma clara y precisa cuales lugares deberá el adolescente dejar de visitar o frecuentar. El juez de Ejecución de Sanciones deberá comunicarle al propietario, administrador o responsable de los locales o lugares que el adolescente tiene prohibido ingresar.

\subsection{Obligación de matricularse en un centro de educación formal o en otro cuyo objetivo sea enseñarle alguna profesión u oficio}

Es una orden de orientación y supervisión que consiste en ordenar al adolescente ingresar y permanecer en algún centro de estudios, sea este de educación formal o vocacional, el juez de Primera Instancia de Adolescentes 
deberá indicar el centro educativo formal o vocacional al que el adolescente debe ingresar o el tipo alternativo de programa educativo que debe seguir. Si no lo hiciere será competencia del juez de Ejecución, en todo caso, se preferirán aquellos centros educativos que se encuentren cerca del medio familiar y social del adolescente. Durante el tiempo que dure esta sanción, el encargado del centro educativo deberá informar al juez de Ejecución sobre la evolución y rendimiento académico del adolescente en el centro de enseñanza o programa respectivo, además procurará el apoyo necesario para que el adolescente continúe con sus estudios.

\subsection{Abstenerse de ingerir bebidas alcohólicas, substancias alucinógenas, enervantes, estupefacientes o tóxicas que produzcan adicción o hábito}

Es una orden de orientación y supervisión que consiste en prohibir al adolescente consumir, durante el tiempo de ejecución de la sanción, este tipo de bebidas o sustancias en cualquier lugar público o privado. Los miembros del equipo técnico elaborarán el plan individual para la ejecución de esta sanción, en el que se establecerá la asistencia a cursos, seminarios o programas que induzcan al joven a eliminar el consumo y adicción de ese tipo de sustancias o drogas. En otras palabras, consiste en la obligación por parte del adolescente de recibir el tratamiento, de reconocer el injusto y manifestar el deseo de corregirse; a cambio, la sociedad está dispuesta a prescindir de un castigo más severo.

\subsection{Obligación de someterse a programas de tipo formativo, cultural, educativo, profesional, laboral, de educación sexual, de educación vial u otros similares}

Es una orden de orientación y supervisión que consiste en educar al adolescente, formándolo sobre determinados temas, los cuales deben tener relación con el hecho delictivo que haya cometido. 


\subsection{Ordenar el internamiento terapéutico del niño, niña o adolescente o el tratamiento ambulatorio en un centro especializado de salud, público o privado, para desintoxicarlos o eliminar su adicción a las drogas antes mencionadas}

Este tipo de sanción socioeducativa se aplica a aquellos adolescentes que cometan actos delictivos relacionados con el consumo de drogas u otro tipo de estupefacientes; consiste en ordenar al adolescente participar en un programa público o privado, que lo conduzca a eliminar la dependencia de drogas o a cualquier otro tipo de substancias que provoquen adicción. La Ley no solo regula el tratamiento de adicciones sino también se refiere a sus alteraciones en su percepción, anomalías o alteraciones psíquicas o alteraciones en la percepción que determinen una alteración grave de la realidad.

Existen dos tipos de tratamiento, uno ambulatorio y otro internamiento terapéutico. Cuando la orden consiste en un tratamiento ambulatorio, se debe tomar en cuenta no interferir en las actividades educativas y laborales del adolescente, en este caso el profesional o la institución o el encargado del tratamiento debe ajustarse al horario del adolescente, quien queda obligado a asistir al lugar designado con la periodicidad requerida. Este tipo de tratamiento no puede durar más de doce meses. Cuando la orden del juez consista en un tratamiento de internamiento terapéutico, este debe realizarse en un establecimiento especial, dependiendo del caso de que se trate, lamentablemente, la Secretaría de Bienestar Social no cuenta con un Programa adecuado para aplicar esta sanción, así como hasta la fecha no se le ha remitido ningún adolescente sancionado. Sin embargo, sí es parte de los programas de libertad asistida y prestación de servicios a la comunidad. Pero, considero que, por lo importante del tema, necesita de un programa para controlarlo. Este tipo de internamiento no puede durar más de cuatro meses, y debe informarse periódicamente al juez de los avances del mismo. En caso de que el adolescente rechace el tratamiento ordenado, la autoridad o institución encargada debe informar al juez para que este aplique otra sanción adecuada a las circunstancias del adolescente. 


\subsection{Privación del permiso de conducir}

Este tipo de sanción socioeducativa se aplica ante todo al adolescente responsable de delitos contra la seguridad del tránsito y delitos o faltas que se hubieren cometido usando un vehículo automotor. Consiste en privar temporalmente al adolescente de su permiso de conducir o de su derecho a obtenerlo, con el fin de hacerle conciencia sobre la responsabilidad que tienen las personas que se encuentran al frente de un timón. No podrá imponerse por un período mayor a los 2 años, y por el tipo de delitos es el juez de paz el que tiene la competencia para aplicar la sanción. La autoridad que controla la ejecución de la medida es el juez de Ejecución.

\subsection{Sanciones privativas de libertad}

He aquí una sanción socioeducativa controversial, sobre todo si tomamos en cuenta que nuestra Constitución Política de la República establece que su tratamiento debe estar orientado a una educación propia para la niñez y la juventud, por su condición especial debe ser atendida por centros y personal especializado. Constitucionalmente se tiene la llave para aplicar una sanción socioeducativa encaminada a corregir una conducta delictiva que amerite una sanción privativa de libertad. Además, atendiendo al principio de ultima Ratio establecido en tratados y convenios internacionales, que regula que solamente en última instancia, y cuando no pueda proceder otro tipo de medida, se debe recurrir a esta. Entendemos que este tipo de sanción solo se puede aplicar en caso de que el adolescente cometa delitos de tal gravedad que el juez no tenga otra salida que aplicar una sanción privativa de libertad. Las modalidades de privación de libertad son las siguientes:

\subsection{Privación de libertad domiciliaria}

Esta sanción consiste en privar la libertad del adolescente en su casa de habitación con su familia, a quien no se le permitirá salir de su domicilio por su propia voluntad. En caso sea inconveniente que la sanción se aplique con su familia, puede realizarse en casa de algún familiar, y en caso no se pueda contar con algún familiar, se puede encargar el cuidado del adolescente en alguna institución adecuada o en vivienda de personas interesadas en cuidarlo. 
Esta sanción no puede durar más de un año, y en ningún caso puede interferir con la asistencia del adolescente a su centro educativo o lugar de trabajo. El encargado de supervisar el cumplimiento de esta sanción es el trabajador social designado por el juez de Ejecución de Sanciones. En caso de incumplimiento del adolescente la juez de Ejecución puede modificar la sanción.

\subsection{Privación de libertad durante el tiempo libre}

Esta modalidad consiste en una restricción a la libertad del adolescente que debe cumplirse en un centro especializado en cualquier momento del día o de la semana en que el joven no esté realizando actividades laborales o de estudio, su duración no debe exceder de ocho meses. El adolescente reside con su familia y solamente durante su tiempo libre se debe trasladar al centro especializado de cumplimiento. Es aconsejable que este tipo de establecimientos no tengan seguridad extrema, y es muy importante que cuente con personal especializado, áreas y condiciones adecuadas para el cumplimiento efectivo de esta sanción. Esta medida socioeducativa ha sido una alternativa a la clásica privación de libertad, con esto se procura que el adolescente conserve el ritmo diario, normal y el entorno social en que se desarrolla, en armonía con el nuevo paradigma de la justicia de juvenil que persigue la reeducación del adolescente.

Pero se tiene el inconveniente de que la Secretaría de Bienestar Social no cuenta con un programa adecuado para esta sanción, como tampoco cuenta con la infraestructura adecuada. Por lo tanto, no existe ningún antecedente de que se haya aplicado por un juez esta sanción.

\subsection{Privación de libertad en centros especializados durante fines de semana, comprendido desde el sábado, de las ocho horas, hasta el domingo a las dieciocho horas.}

Es una medida socioeducativa que consiste en que el adolescente es enviado a centros especializados solo durante los fines de semana, desde el sábado de las ocho horas hasta el domingo hasta las dieciocho horas, con el objetivo de realizar actividades que promuevan su educación integral y el desarrollo de una conciencia social que evite que en el futuro continúe cometiendo hechos delictivos. Su duración no puede ser mayor a ocho meses. 
La Secretaría de Bienestar Social no cuenta con un programa adecuado para la aplicación de esta sanción, así como tampoco con un centro especializado para este efecto.

\subsection{Privación de libertad en centros especializados de cumplimiento en régimen abierto, semiabierto o cerrado.}

Es una sanción socioeducativa dirigida a restringir la libertad de circulación y el libre traslado de los adolescentes, manteniéndolas en un recinto durante determinado tiempo. En este caso, el adolescente cumple un proceso de institucionalización, y es muy importante que se procure una afectación mínima de sus derechos, en este sentido ha de procurarse que solo se restrinja la libertad ambulatoria, en tanto todos los demás derechos no deben verse limitados. Además, únicamente se justifica por fines de prevención especial, es decir, para influir en forma particular en la vida futura del adolescente y procurar que lleve una vida sin cometer nuevos delitos.

El adolescente se encuentra internado en un centro especializado del que no se le permite salir por su propia voluntad, sin que no sea ordenado por la autoridad judicial. Es muy importante tomar en cuenta que esta medida reviste un carácter excepcional, es decir, el juez siempre debe completar la posibilidad de ampliar cualquier otro tipo de sanción menos drástica antes de disponer de esta, por lo tanto, debe justificar la necesidad de su imposición además de sustentar los fines educativos que se buscan al imponer esta medida socioeducativa.

No se debe confundir esta sanción con la pena de prisión establecida para los adultos, ya que responde a otras necesidades, presupuestos y fines muy diferentes, como que el lugar de ejecución de la sanción debe estar condicionado especialmente para este fin, y han de ser centros diferentes a los destinados a los delincuentes sujetos a la legislación penal común. Además, la sanción de internamiento en centro especializado se caracteriza porque debe cumplir los fines de procurar protección integral y el interés superior del niño, así como los fines de prevención especial. También, como ya mencioné anteriormente, durante el cumplimiento de la sanción se debe garantizar que el adolescente, 
como sujeto en formación, disfrute de todos sus derechos con excepción de los restringidos en la sentencia.

La Ley de Protección Integral de la Niñez y Adolescencia en su artículo 253 regula tres clases de regímenes de privación de libertad en centro especial de cumplimiento y estas son:

\subsubsection{Régimen abierto}

Consiste en que el adolescente tendrá como residencia habitual el centro especial de cumplimiento, estableciéndose en su plan individual y proyecto educativo que todas sus actividades socioeducativas se llevarán a cabo fuera del centro, en los servicios del entorno. No existe un centro especializado para poder cumplir con este tipo de sanción, así como ningún programa por parte de la Secretaría de Bienestar Social, y ningún antecedente de su aplicación hasta la fecha.

\subsubsection{Régimen semiabierto.}

Consiste en que el adolescente tendrá como residencia habitual el centro especial de cumplimiento, estableciéndose en su plan individual y proyecto educativo que algunas de sus actividades formativas, educativas, laborales y de descanso se llevarán a cabo fuera del centro. No existe ningún centro especializado para poder cumplir con este tipo de sanción, así como ningún programa por parte de la Secretaría de Bienestar Social. Sin embargo, sí existe un antecedente, en el mes de junio del año 2005, la juez de Control de Ejecución de sanciones modificó una sanción socioeducativa, otorgándole a una interna el beneficio de poder visitar a su familia los fines de semana, sin embargo, según la Secretaría de Bienestar Social, no existe ningún programa adecuado para poder controlar este tipo de sanción.

\subsubsection{Régimen cerrado}

Consiste en que el adolescente residirá en el centro estableciéndose en su plan individual y proyecto educativo que todas sus actividades socioeducativas 
serán desarrolladas dentro del propio centro. A diferencia de las anteriores esta sanción sí cuenta con un programa establecido, contando para el efecto con dos Centros de Detención de Privación de Libertad, uno para mujeres y otro para hombres.

Este tipo de sanción socioeducativa por su carácter excepcional requiere que se cumplan dos requisitos para aplicarla:

a. Cuando se trate de una conducta realizada mediante grave amenaza o violencia hacia las personas y la propiedad y se trate de un delito contra la vida, la libertad sexual, la libertad individual, robo agravado y tráfico de estupefacientes.

b. Cuando se trate de delitos dolosos sancionados en el Código Penal o leyes especiales, para mayores de edad con pena de prisión superior a seis años.

Esta sanción durará un período máximo de seis años para los adolescentes entre 15 y 18 años, y de dos años para los comprendidos entre los 13 y 15 años. Nunca se podrá aplicar cuando no proceda contra un adulto según el Código Penal. Al fijarla, el juez debe tomar en cuenta las circunstancias personales, familiares, sociales y educativas del adolescente. $\mathrm{Y}$ en caso el adolescente cumpla la mayoría de edad y no ha terminado su sanción, debe ser trasladado a otro centro especial, pero nunca a un centro de cumplimiento de condena para adultos. También en este caso no contamos con ningún centro adecuado ni la Secretaría de Bienestar Social cuenta con el programa respectivo. 


\section{CAPÍTULO IV}

\section{Violación a los derechos de las niñas víctimas, respecto a la aplicabilidad de la conciliación en el procedimiento abreviado}

El Derecho de la Niñez y de la Adolescencia es el conjunto de normas jurídicas que rigen y regulan los derechos y deberes de los niños y adolescentes, su conducta y el sistema de protección de los mismos; tiene funciones específicas como proteger a los niños y adolescentes y al mismo tiempo reconocer sus derechos y velar porque estos sean respetados. Sin embargo, a través de la historia, se dio una indiferencia jurídica (situación irregular), que implicaba la "protección" a los menores, pero a través de su aplicación, se vio reflejada la falta de importancia hacia los mismos, debido a que los tomaban como seres no pensantes, los cuales no tenían ni voz ni voto no solo dentro del ámbito jurídico, sino que del ámbito social también.

Una característica importante que se dio en esa época de la situación irregular, fue la desigualdad, es decir, tenían en un concepto muy bajo a los menores, de tal forma que cuando los mismos eran objetos de delitos o faltas, estos eran ingresados en los mismos centros de detención que los adultos, los cuales al final, en lugar de ser rehabilitados y reintegrados a la sociedad, salían en primer lugar, traumatizados del mismo y en segundo lugar, mucho peor de lo que ingresaron, cuando muchas veces solo fueron objetos de faltas.

Posteriormente, se inicia la época de protección integral cuando entra en vigencia la Convención de los Derechos del Niño, la cual trajo consigo una revolución jurídica a favor de los niños y adolescentes, ya que se empezaron a reconocer sus derechos y se determinó que estos no podían tener el mismo trato que los adultos, sino que debía haber un tratamiento especializado en ese campo.

El contenido de las fases o procedimiento de adolescentes en conflicto con la ley penal, no es adecuado para la investigación y juzgamiento de hechos delictivos cometidos por adolescentes, pues utiliza el instituto jurídico de la 
conciliación en el procedimiento específico abreviado para resolver determinado conflicto penal, y con ello se vulnera el derecho humano de la niña víctima, por parte del Estado y sus progenitores, lo cual se encuentra previsto en la Convención Interamericana para Prevenir Sancionar y Erradicar la Violencia contra la Mujer.

En la actualidad, con la derogación del Código de Menores y el surgimiento de la Ley de Protección Integral de la Niñez y la Adolescencia en el año 2003, se busca que la doctrina de la protección integral sea aplicada de forma correcta en Guatemala a favor de los niños y adolescentes. Sin embargo, en algunos momentos, ha surgido la duda si se aplica correctamente esta doctrina y si se vulneran algunos derechos de los niños, especialmente las niñas, por lo que, en la presente investigación, se busca hacer un análisis del por qué resulta inadecuada la utilización de la conciliación para resolver determinado conflicto penal relacionado con adolescentes, específicamente en los delitos de violencia sexual en donde las víctimas son niñas, por lo que se busca analizar el contenido de los artículos 171 (objetivos del proceso de adolescentes en conflicto con la ley penal), 184 (terminación del proceso), 185 (conciliación), 186 (naturaleza de la conciliación), 187 (procedencia de la conciliación), 188 (audiencia de conciliación), 189 (acta de conciliación), 190 (obligaciones pactadas en la conciliación), 191 (responsabilidad de los representantes legales), 192 (incumplimiento injustificado), 202 (facultad del Ministerio Público de solicitar la conciliación, oportunidad y remisión, durante la investigación), todos del Decreto número 27-2003 del Congreso de la República de Guatemala, "Ley de Protección Integral de la Niñez y Adolescencia” y, 141 referente a la posibilidad de aplicar supletoriamente las disposiciones del Código Procesal Penal, al proceso de menores de edad, todo aquello que no se encuentre regulado de manera expresa en la ley antes indicada.

De la intelección e integración de las normas contenidas en artículos 185 187, 188 y 189 de la Ley de Protección Integral de la Niñez y la Adolescencia, se colige que, estas prevén como mecanismo procesal de finalizar el proceso anticipadamente, la audiencia y el acto de la conciliación, regulado como uno de los efectos, la suspensión del procedimiento, el cual está condicionado a " $\boldsymbol{l} \boldsymbol{a}$ inexistencia de violencia grave contra las personas". 
Sin embargo, algunos Jueces de Primera Instancia de Adolescentes en Conflicto con la Ley Penal, acceden a su aplicación, sin antes analizar debidamente los hechos acaecidos, las normas jurídicas aplicables al caso, lo que provoca una equivocada subsunción a las normas jurídicas que regulan el procedimiento de menores antes aludido, cuando es notorio que se ha cometido delito grave contra de las niñas víctimas, contraviniendo de esa manera lo previsto en el artículo 185 de la Ley de Protección Integral de la Niñez y Adolescencia, pero especialmente las convenciones internacionales en materia de Derechos Humanos, Convención para la Eliminación de Todas las Formas de Discriminación contra la Mujer en sus siglas "Cedaw", la Convención Interamericana para prevenir, sancionar y erradicar la Violencia contra la Mujer "Belém Do Pará" y la Convención sobre los derechos del niño.

Para analizar la ausencia de la gravedad del hecho cometido por un adolescente, debe examinarse la acción del trasgresor y el daño producido por este, el grado de afectación psicológico y físico al bien jurídico tutelado, es decir, la indemnidad sexual de las niñas víctimas, a lo que los tratadistas denominan violencia vis absoluta y vis compulsiva.

La primera implica fuerza sobre la persona, golpearla, secuestrarla. La segunda es la intimidación, la amenaza de provocarle un mal grave; esa amenaza debe ser tal que desaparezca la voluntad en una persona razonable, provoque temor grave. La segunda, es la intimidación, la amenaza de provocarle un mal grave, esa amenaza debe ser tal, que desaparezca la voluntad en una persona razonable y le ocasione temor grave. Es decir, debe ser de tal naturaleza que le cause impresión profunda en su estado anímico y le inspiren temor de exponer su persona o su honra.

Por lo tanto, para calificar la violencia o la intimidación [cualquiera de las dos anteriores], se debe atender a la edad de la víctima, sexo, condición y demás circunstancias que puedan influir sobre su gravedad.

De lo anterior, puede colegirse, que las normas antes citadas, se refieren a delitos, donde la gravedad de las consecuencias está ausente, por ejemplo, robo y hurto, en donde el despojo de las pertenencias de la víctima se da de 
una manera subrepticia [pues en muchas ocasiones, la víctima no se percata de que ha sido despojada de sus pertenencias], empero en delitos tales como la violación, agresión sexual y sus diferentes formas, sobre todo si la víctima es una niña, homicidio o asesinato, por mencionar algunos, la figura de la conciliación lógicamente deviene improcedente.

Ahora bien, el artículo 141 de la Ley de Protección Integral de la Niñez y Adolescencia, establece que en todo lo que no se encuentra regulado de manera expresa en esa ley, deberá aplicarse supletoriamente la legislación penal y el Código Penal, siempre y cuando, no contradigan normas expresas de aquella ley. Por su parte, el artículo 203 literal d) de la ley antes citada contempla el procedimiento abreviado, no existiendo otra norma dentro de esa ley que se refiera a este procedimiento específico, lo que equivale a que deba utilizase supletoriamente lo previsto para este instituto, el proceso previsto en el Código Procesal Penal.

En aplicación supletoria de aquella ley, el Ministerio Público procede conforme a lo dispuesto en el artículo 464 del Código Procesal Penal, el cual prevé, que, si el Ministerio Público estimase suficiente la imposición de una pena no mayor a cinco años de privación de libertad, o de una pena no privativa de libertad, o aun en forma conjunta, podrá solicitar que se proceda según este título, concretando su requerimiento ante el juez de primera instancia en el procedimiento intermedio. Para ello el Ministerio Público deberá contar con el acuerdo del imputado y su defensor, que se extenderá a la admisión de hecho descrito en la acusación y su participación en él, y la aceptación de la vía propuesta, por lo que la existencia de varios imputados en un mismo procedimiento no inhibirá la aplicación de esta regla a alguno de ellos.

Se debe tomar en cuenta que tal requerimiento debe plantearse durante el procedimiento intermedio y de que ya debe estar planteada la acusación, tomándose en cuenta como punto primordial, la pena.

En los delitos de violación y sus formas de agravación de la pena calificada, específicamente las cuales superan, en su mínimo, los 5 años, se aplica el procedimiento intermedio. 
No obstante, lo anterior se aplica en esta clase de delitos, y nuevamente surge la disyuntiva respecto dela aplicación dela conciliación y del procedimiento abreviado en esta clase de delitos, pues cuando estas decisiones son recurridas, las mismas son confirmadas por la Sala de la Corte de Apelaciones de la Niñez y Adolescencia. Asimismo, en los delitos de violencia contra la mujer.

Asimismo, los artículos 7, 8 y 9 de la Convención Interamericana para prevenir, sancionar y erradicar la Violencia contra la Mujer "Belém Do Pará, establecen los deberes de los Estados, lo cuales deben condenar todas las formas de violencia contra la mujer y deben adoptar todos los medios apropiados y sin dilación política orientados a prevenir, sancionar y erradicar dicha violencia, estableciendo procedimientos legales justos y eficaces para la mujer que haya sido sometida a violencia, que incluyan, entre otros, medidas de protección, un juicio oportuno y acceso efectivo a tales procedimientos, estableciendo los mecanismos judiciales para asegurar que la mujer objeto de violencia, tenga acceso efectivo a tales procedimientos, tenga acceso efectivo a resarcimiento, reparación del daño u otros medios de compensación justos y eficaces, especialmente tomando en cuenta la situación de vulnerabilidad a la violencia que pueda sufrir la mujer en razón, entre otras, de su raza o de su condición étnica. En ese sentido se considera mujer objeto de violencia cuando esta sea menor de edad.

Ahora bien, desde la teoría de género, tomando en cuenta la existencia de sistemas en los que se expresan relaciones de poder o de abuso de poder, que algunas sociedades elaboran a partir de la diferencia sexual, se caracteriza por el uso de mecanismos y técnicas para el control de las capacidades femeninas especialmente en las niñas víctimas que si bien tienen derecho a opinar sobre asuntos que le competen, también lo es que una conciliación entre víctima y victimario en términos de igualdad y favorecida por el sistema de justicia no es lo más recomendable ni equitativo en términos de justicia para la víctima (no obstante que los padres, tutores o cualquier otro representante legal de la misma, se encuentre presente en la audiencia de conciliación de mérito) y tomando en consideración que la mencionada audiencia de conciliación lo que trata primordialmente es que la parte activa del delito dé cierta cantidad de dinero a la parte pasiva, y con ello se estaría equiparando la indemnización como un 
sustituto de la persecución penal, sin tomar en cuenta todos los aspectos que afectan a las víctimas, en este caso, las niñas.

Resulta negativo para la niña víctima que por una cantidad de dinero se pretenda reparar el daño causado, daño que repercutirá por el resto de su vida e influirá en su desarrollo personal, pues con esta acción se le discrimina por su condición de mujer, privilegiando al agresor, que casi siempre es un hombre que la víctima, mujer menor de edad.

Con la conciliación, se privilegia al trasgresor de la ley penal, pues se le beneficia en que puede lograr su libertad por mecanismos en los cuales se desnaturaliza la ley, tanto por juzgadores, fiscales como defensores, impactando de esa manera en la sociedad, pues no dictan sus resoluciones atendiendo a un enfoque de género y tomando en consideración, específicamente, que la víctima sea mujer menor de edad.

La cultura patriarcal que se realiza desde lo patricéntrico y que unido al androcentrismo como el orden patriarcal en el centro de la explicación del mundo, se da como la estructura del orden, se reproduce en el ordenamiento legal guatemalteco, pues este contiene normas de diversas jerarquías, siendo uno de ellos el sistema penal y procesal penal, que a pesar de haber introducido doctrinas modernas de Derecho, mantiene normas discriminatorias como la que es sujeto de análisis en el presente trabajo de investigación.

No obstante, lo previsto en aquellos instrumentos internacionales mencionados, se ha visto en la práctica forense, que algunos administradores de justicia, llámese jueces, fiscales, en los delitos antes indicados, han aplicado la figura jurídica de la conciliación y el procedimiento específico abreviado, aun y cuando, estos no proceden, pues las disposiciones legales antes referidas, lo limitan. En este sentido, se reitera, que es importante considerar aspectos notables que permitan al sistema de justicia de Guatemala, no aplicar esta medida, pues la gravedad del delito de agresión sexual y de violación, estriban entre las diversas consecuencias físicas que pueden ser ocasionadas por la agresión sexual. Podemos citar: contagio de enfermedades venéreas, lesiones internas que pueden llegar a provocar incapacidad permanente para procrear, o severos 
daños a los órganos reproductores. A veces incluso se requieren intervenciones quirúrgicas de importancia. Además, las consecuencias psicológicas pueden ser igualmente graves, pues las víctimas pueden padecer un temor permanente a sufrir un ataque similar, la vivencia criminal se actualiza, revive y perpetúa. Este temor a la repetición puede producir ansiedad, depresiones y proceso neurótico, pudiendo dar lugar a la propia autoculpabilización de responsabilidad y llevar a la víctima a que tenga problemas posteriores para sostener una relación adecuada con personas del sexo contrario o que pueda mantenerse una vida sexual satisfactoria.

Para la prevención, sanción y erradicación de la violencia contra las mujeres, la legislación es sin duda alguna una medida importante, sin embargo, la legislación debe ir aparejada de procesos de sensibilización a los aplicadores y las aplicadoras de justicia, de procesos de reeducación en los cuales se trabaje la eliminación de mitos y prejuicios en torno a la violencia contra las mujeres y más importante aún, campañas permanentes mediante las cuales las mujeres y las niñas conozcan sus derechos y los recursos y apoyos con los cuales cuentan si quieren denunciar.

Se han desarrollado "Programa de Formación en Derechos Humanos de las Mujeres", dirigido al personal del Ministerio Público, Organismo Judicial, Instituto de la Defensa Pública Penal y el Ministerio de Gobernación. Una medida de formación muy importante es la que desarrolla la Escuela de Estudios Judiciales, la cual tiene como función el formar y capacitar al personal del Organismo Judicial teniendo como eje transversal la perspectiva de género y los derechos humanos, sin embargo, se advierten falencias en la administración de justicia en cuanto al enfoque de género tendientes a eliminar todo tipo de violencia contra las mujeres.

Desde la teoría de género, tomando en cuenta la existencia de sistemas en los que se expresan relaciones de poder o de abuso de poder, que algunas sociedades elaboran a partir de la diferencia sexual, se caracteriza por el uso de mecanismos y técnicas para el control de las capacidades femeninas especialmente en las niñas víctimas que si bien tienen derecho a opinar sobre asuntos que les competen, también lo es que una conciliación entre víctima y 
victimario en términos de igualdad y favorecida por el sistema de justicia no es lo más recomendable ni equitativo en términos de justicia para la víctima (no obstante que los padres, tutores o cualquier otro representante legal de la misma, se encuentre presente en la audiencia de conciliación de mérito) y tomando en consideración que la mencionada audiencia de conciliación lo que trata primordialmente es que la parte activa del delito dé cierta cantidad de dinero a la parte pasiva, y con ello se estaría equiparando la indemnización como un sustituto de la persecución penal, sin tomar en cuenta todos los aspectos que afectan a las víctimas, en este caso, las niñas. El abuso sexual también abarca a los niños, y como ya se dijo, es una de las peores formas de violencia. Las víctimas sufren un daño irreparable a su integridad física, psíquica y moral. Se daña su derecho a la integridad, la intimidad, la privacidad y, principalmente, se vulnera el derecho a no ser expuesto a ningún tipo de violencia, abuso, explotación o malos tratos. Estos derechos se encuentran protegidos a nivel internacional por la Convención sobre los Derechos del Niño y a nivel nacional por la Ley de Protección Integral de la Niñez y Adolescencia, entre otros y, en estos casos, también resulta improcedente la conciliación, dada la gravedad del daño, que en ocasiones resulta irreparable.

Resulta negativo para la niña víctima, que por una cantidad de dinero, se pretenda reparar el daño causado, daño que repercutirá por el resto de su vida e influirá en su desarrollo personal, pues con esta acción se le discrimina por su condición de mujer, privilegiando al agresor, que casi siempre es un hombre, y la víctima, una mujer menor de edad, pues los juzgadores no advierten la gravedad de las consecuencias del delito, las cuales son irreparables, pues a pesar de que reciban tratamiento psicológico, ese trauma sufrido, las acompañara el resto de sus vidas.

Con la conciliación se privilegia al trasgresor de la ley penal, pues se le beneficia en que puede lograr su libertad por mecanismos en los cuales se desnaturaliza la ley, tanto por juzgadores, fiscales como defensores, impactando de esa manera en la sociedad, pues no dictan sus resoluciones atendiendo a un enfoque de género y tomando en consideración, específicamente, que la víctima sea mujer menor de edad. 


\subsection{Concepto de víctima}

En el proceso penal se ha abordado con mucha atención la violación a los derechos del sindicado, olvidándose por completo de la víctima, ya que desde la Antigüedad se ha tenido la idea, que con el hecho de que el sindicado pague su culpa purgando una condena, se ha remediado el daño ocasionado a la víctima, y vengado el agravió recibido. "La idea de la compensación está, como la idea del castigo y la venganza, unida a la historia de la humanidad, si bien no en forma claramente delimitada, ya que se confunde con estos dos conceptos en una amalgama de procedimientos que son a veces impuestos por la comunidad o el Estado, a veces por la familia de la víctima o por la misma víctima y que tienen en la mayoría de los casos el carácter de punición y de advertencia o prevención, más que el de reparación o descompensación" (Rodríguez González, Ramiro. La victimología: 47).

El Código Procesal Penal guatemalteco en su artículo 117 denomina al agraviado como: "1) A la víctima afectada por la comisión del delito. 2) Al cónyuge, a los padres y a los hijos de la víctima y a la persona que conviva con ella en el momento de cometerse el delito. 3) A los representantes de una sociedad por los delitos cometidos contra la misma y a los socios respecto a los cometidos por quienes la dirijan, administren o controlen; y 4) A las asociaciones en los delitos que afecten intereses colectivos o difusos, siempre que el objeto de la asociación se vincule directamente con dichos intereses".

\subsubsection{Concepto de niña víctima}

Para efectos de la Convención de los Derechos del Niño, específicamente en su artículo 1, se entiende por niño "todo ser humano menor de 18 años de edad, salvo que, en virtud de la ley que le sea aplicable, haya alcanzado antes la mayoría de edad".

En la Ley de Protección Integral de la Niñez y Adolescencia en el artículo dos, define para efectos de esa ley: "se considera niño o niña a toda persona desde su concepción hasta que cumple 13 años de edad, y adolescente a toda aquella desde los 13 hasta que cumple 18 años de edad". 
Partiendo de la Declaración de Naciones Unidas, "se puede definir como niños o niñas víctimas a las personas menores de dieciocho años de edad que, individual o colectivamente, hayan sufrido daños, incluido, lesiones físicas o mentales, sufrimiento emocional, pérdida financiera o menoscabo sustancial de su derechos fundamentales, como consecuencia de acciones $u$ omisiones que violen la legislación penal vigente en los Estados miembros, incluida la que proscribe el abuso de poder" (Rodríguez Barillas, Alejandro. Los derechos de la niñez víctima en el proceso penal guatemalteco: 5 ).

En la Convención sobre los Derechos del Niño, artículo dos numeral uno, los Estados Partes se obligaron a "respetar los derechos enunciados en la misma y aseguraron su aplicación a cada niño sujeto a su jurisdicción, sin distinción alguna, independientemente de la raza, el color, el sexo, el idioma, la religión, la opinión política o de otra índole, el origen nacional, étnico o social, la posición económica, los impedimentos físicos, el nacimiento o cualquier otra condición del niño, de sus padres o de sus representantes legales".

Rodríguez Barillas expresa que "no cabe duda que los niños y niñas se encuentran entre los principales grupos victimizados, consecuencia de su vulnerabilidad física que les impide defenderse frente agresores que son más fuertes, de su tradicional sumisión ante la autoridad de los adultos, de su situación de dependencia económica, de su inexperiencia, que le hace desconocer los mecanismos para poder denunciar el hecho y llevar adelante un proceso penal frente a sus agresores"; también comenta el autor citado que: "por otro lado, los niños son víctimas de maltrato físico y abuso sexual por familiares cercanos, incluyendo sus padres. Son víctimas de explotación sexual, de la explotación laboral, etc. Todo ello debido precisamente a la posición de vulnerabilidad especial en la cual se encuentran y a la ausencia de políticas públicas a favor de la defensa y protección de los derechos de la niñez".

\subsection{Grados de victimización}

El término victimización se usa para describir los efectos que produce el delito en la víctima, y significa según, Mendelson citado por Rodríguez Barillas, "el efecto de sufrir un daño, directa o indirectamente por un delito; la victimización supone los daños que sufre una persona, grupo o sector que es ofue objeto de un delito o infracción". 
Para evaluar de mejor forma los distintos efectos que se generan sobre la víctima como consecuencia de un hecho delictivo, García Pablos de Molina, citado también por Rodríguez Barillas, menciona que se han establecido grados de victimización, habiéndose definido tres niveles fundamentalmente:

a. La victimización primaria, orientada a los daños directos e inmediatos del hecho delictivo.

b. La victimización secundaria, en donde se analizan los daños causados por la intervención del sistema penal sobre la víctima.

c. La victimización terciaria, que son los daños que la sociedad causa a la víctima.

\subsubsection{Victimización primaria sobre los niños, niñas y adolescentes}

Esta victimización es la que sufre una niño o adolescente, en el momento mismo de que se comete un delito en su contra, en virtud de sufrir directamente el efecto del delito, o ya bien por resultar agraviado por el mismo. "La victimización primaria hace referencia a la víctima individual. En este sentido, todo menor de edad puede ser víctima en sentido amplio y en sentido estricto. Interesa estudiar únicamente la victimización primaria en sentido estricto, es decir, en donde la niña, niño es la víctima directa del delito”.

\subsubsection{Victimización secundaria sobre las niñas, niños y adolescentes}

Esta surge cuando los niños y adolescentes resultan siendo afectados por la mala o no intervención de los operadores de justicia, es decir, que la victimización surge al inicio, desarrollo y debate del proceso penal. "La victimización secundaria tiene lugar cuando la víctima del delito entra en contacto con la administración de justicia penal. En efecto, la actuación de las instancias de control penal formal (policía, jueces, etc.) multiplica y agrava el mal que ocasiona el delito mismo. Por ello, se puede definir la victimización secundaria como los sufrimientos inferidos por las instituciones encargadas de hacer justicia, a las víctimas y testigos y mayormente a los sujetos pasivos de un delito" (Rodríguez: 15). 
Beristaín, citado por Rodríguez Barillas señala que "gracias a numerosas investigaciones, se está concientizando que quien padece un delito, al momento de acudir a las agencias encargadas de la administración de justicia, en vez de encontrar la respuesta adecuada a sus necesidades y derechos, recibe una serie de posteriores e indebidos sufrimientos e incomprensiones, en las diversas etapas del proceso penal, desde la intervención de la policía hasta la de la autoridad penitenciaria, pasando por la judicial y también la pericial (Rodríguez: 15,16).

La victimización secundaria se entiende entonces como aquellos sufrimientos que las víctimas experimentan por parte de la actuación de las instituciones encargadas de procurar e impartir justicia: Ministerio Público, policías, jueces, peritos y aquellos servidores e instancias públicas con competencia en la materia. En este caso, se puede afirmar que la victimización secundaria se presenta no por el acto delictivo, sino como consecuencia directa de la respuesta institucional que se da a la víctima: a veces puede derivar de un completo rechazo de los derechos humanos de las víctimas de grupos culturales en particular, clases o un género en específico, mediante una negativa para reconocer su experiencia como una victimización del delito. Ello puede resultar de una conducta imprudente o inapropiada por la policía o de otras autoridades del sistema de justicia.

Más sutilmente el proceso entero de investigación criminal y del proceso en sí, pueden causar victimización secundaria, por parte de la investigación, a través de las decisiones ya sea para persecución o no, la ausencia de normas para perseguir el delito, el propio proceso penal, y la sentencia del delincuente o de su eventual liberación. La victimización secundaria a través del proceso de justicia penal puede ocurrir debido a las dificultades entre el equilibrio de los derechos de la víctima contra los derechos del acusado o delincuente. Más usualmente, de cualquier forma ocurre porque aquellos responsables de ordenar los procesos de justicia penal lo hagan sin tomar en cuenta la perspectiva de la víctima.

Existen otras instituciones en las que se puede producir victimización secundaria, por ejemplo, en los hospitales, las instituciones o servicios de asistencia a víctimas, que por razones diversas o incluso por sus propias políticas y procedimientos pueden dar origen a este fenómeno. 
En este caso, también se pueden considerar a los Gobiernos de los Estados o sus Poderes Legislativos que no promulgan la legislación correspondiente a violencia familiar. Las consecuencias para este tipo de victimización serán de orden psicológico, emocional, moral y económico.

\subsubsection{Victimización terciaria}

La estigmatización que la sociedad realiza luego sobre la víctima se conoce como victimización terciaria.

Esta victimización según indica Rodríguez Barillas, "se refiere directamente al etiquetamiento y estigmatización que hace la sociedad contra la víctima, provocándole un sufrimiento añadido. La estigmatización que la sociedad puede ejercer sobre un niño o niña puede tener efectos terribles en su desarrollo psicológico o emocional, por lo que ha de mantenerse la mayor privacidad posible al respecto. La publicidad negativa que puede darse contra los niños agravaría la estigmatización social. En este sentido, se requiere de una campaña de capacitación a los medios de comunicación en el tratamiento de las noticias de menores de edad, para evitar padecimientos provenientes de la publicidad del hecho. El tratamiento de las noticias relacionadas con las víctimas tiene que ser abordado con el mayor profesionalismo, para excluir los aspectos morbosos o sórdidos de las historias".

Afortunadamente, desde hace algunos años, se está asistiendo, sin embargo, al redescubrimiento de la víctima. La nueva y moderna corriente de opinión se canaliza en lo que se conoce como "victimología". Parece con ello ponerse de nuevo en laza la reparación de las víctimas de los delitos, alcanzando estas además distintos grados de conceptualización y clasificación, si están unidas por comunes propósitos; dejando de ser, nuevamente, meras abstracciones dogmáticas.

Desde otro punto de vista, la victimización terciaria es aquella en que la propia víctima asume su papel con resignación y conciencia, convencida (o) de que esa nueva imagen de sí misma (o) le conviene para obtener un resultado exitoso. 
Esta acción consiste en que la víctima utiliza su imagen para lograr de las autoridades y de la sociedad el reconocimiento de la situación y victimización de que es objeto; en este caso, los organismos no gubernamentales, por ejemplo, aprovechan la oportunidad de definir a los niños y adolescentes víctimas como un grupo discriminado y violentado. O bien se utiliza a la menor víctima, para aprovechar foros, medios de comunicación, medios impresos, etcétera. Aquí podemos mencionar, por ejemplo, todas aquellas acciones que se toman en medios de comunicación, foros y actividades de la sociedad civil que representa a niños y adolescentes víctimas de delitos cometidos por la familia, la sociedad, y las instituciones del Estado, esto para impulsar la legislación y otras acciones en esta materia.

Concretamente, en el caso de la victimización por violencia familiar y en cualquiera de las formas de victimización, el ámbito de las consecuencias económicas ha sido poco estudiado y menos documentado. Los aspectos relativos a recursos son de gran importancia en la prevención, sanción y erradicación de este tipo de violencia.

\subsection{Consecuencias del delito de violación en la niña}

La violación sexual para las mujeres constituye un acto sumamente vergonzoso debido, en parte, a factores culturales y también al atropello de su dignidad al forzarla a un acto que violenta su ser de forma total. Las mujeres que han tenido el coraje de denunciar el hecho e iniciar un proceso judicial para, por una parte, castigar a su agresor y por la otra protegerse a sí mismas de la amenaza contra su integridad que el agresor representa, no han tenido la oportunidad de hacer efectivos los derechos que la Convención de la CEDAW les otorga, ya que las ideas machistas posicionadas históricamente en la humanidad, se encuentran presentes en las prácticas procesales de los funcionarios públicos encargados de investigar el hecho delictivo de la violación, tomando actitudes como la duda y el cuestionamiento hacia la víctima de su responsabilidad en el hecho, haciéndose pensar que el acto ha sido provocado por las víctimas o resistiéndose a aceptar la gravedad del asunto hecho ya que para las sociedades machistas el valor de la mujer se encuentra disminuido al ser sometido a la voluntad del hombre. 
Las consecuencias psicológicas que se han relacionado con la experiencia de abuso sexual infantil, pueden perdurar a lo largo del ciclo evolutivo y configurar, en la edad adulta, los llamados efectos a largo plazo del abuso sexual. También es posible que la víctima no desarrolle problemas aparentes durante la infancia y que estos aparezcan en la adultez.

Se habla de efectos a largo plazo cuando estos se encuentran a partir de los dos años siguientes a la experiencia de abuso, presentándose aproximadamente en un $20 \%$ de las víctimas de abuso sexual infantil.

Los efectos a largo plazo son, comparativamente, menos frecuentes que las consecuencias iniciales, sin embargo, el abuso sexual infantil constituye un importante factor de riesgo para el desarrollo de una gran diversidad de trastornos psicopatológicos en la edad adulta. La información actualmente disponible tampoco permite establecer en esta etapa vital un único síndrome específico, o conjunto de síntomas diferenciados, asociados a la experiencia de abuso sexual, afectando este a diferentes áreas de la vida de la víctima; así como no permite confirmar la existencia de una relación lineal entre la experiencia de abuso sexual infantil y la presencia de problemas psicológicos en la edad adulta, existiendo múltiples variables que parecen incidir en esta relación. Los efectos a largo plazo del abuso sexual infantil han sido considerados especulativos, destacando la dificultad que entraña su estudio, especialmente al ser comparados con las consecuencias iniciales, y principalmente dada su interacción con otro tipo de factores relacionados con el paso del tiempo. Las consecuencias psicológicas que se han relacionado con la experiencia de abuso sexual infantil pueden perdurar a lo largo del ciclo evolutivo y configurar, en la edad adulta, los llamados efectos a largo plazo del abuso sexual. También es posible que la víctima no desarrolle problemas aparentes durante la infancia y que estos aparezcan como problemas nuevos en la adultez.

Las principales consecuencias psicológicas derivadas del delito de violación son: problemas emocionales, problemas de relación, problemas funcionales, problemas de adaptación y problemas sexuales. (http://pepsic. bvsalud.org/scielo.php?script=sci_arttext\&pid=S2220-90262012000100007: fecha de consulta: 6 de octubre de 2017). 


\subsubsection{Problemas emocionales}

Las víctimas de abuso sexual infantil, pueden sufrir trastornos depresivos y bipolares; los síntomas y trastornos de ansiedad, destacando por su elevada frecuencia el trastorno por estrés postraumático; el trastorno límite de la personalidad; así como las conductas autodestructivas (negligencia en las obligaciones, conductas de riesgo, ausencia de autoprotección, entre otras); las conductas auto lesivas; las ideas suicidas e intentos de suicidio; y la baja autoestima (http://pepsic.bvsalud.org/scielo.php?script=sci_ arttext\&pid=S222090262012000100007: fecha de consulta: 6 de octubre de 2017).

\subsubsection{Problemas de relación}

El área de las relaciones interpersonales es una de las que suele quedar más afectada, tanto inicialmente como a largo plazo, en víctimas de abuso sexual infantil. Esta área fue la de mayor por ciento existente en la muestra, casi la totalidad de la misma presenta dificultades en el establecimiento de relaciones con los coetáneos y dificultades en los padres como pareja. Destaca la presencia de un mayor aislamiento y ansiedad social, menor cantidad de amigos y de interacciones sociales, así como bajos niveles de participación en actividades comunitarias. Se observa también un desajuste en las relaciones de pareja, con relaciones inestables y una evaluación negativa de las mismas, entre otras. También aparecen dificultades en la crianza de los hijos, con estilos parentales más permisivos en víctimas de abuso sexual al ser comparados con grupos de control, así como un más frecuente uso del castigo físico ante conflictos con los hijos y una depreciación general del rol maternal. http://pepsic.bvsalud. org/scielo.php?script=sci_arttext\&pid=S222090262012000100007: fecha de consulta: 6 de octubre de 2017).

\subsubsection{Problemas de conducta y adaptación social}

Se observan mayores niveles de hostilidad en víctimas de abuso sexual infantil que en grupos control, así como una mayor presencia de conductas antisociales y trastornos de conducta. Kaufman y Widom (1999), por su parte, 
constataron, mediante un estudio longitudinal (1989-1995), el mayor riesgo de huida del hogar que presentaban las víctimas de maltrato infantil, entre ellas, de abuso sexual infantil, en comparación con un grupo control. A su vez, la conducta de huida del hogar, así como el haber sufrido abuso sexual infantil, incrementaban el riesgo de delinquir y de ser arrestado por delitos diversos.

\subsubsection{Problemas funcionales}

Uno de los problemas que afecta a las funciones físicas de estas víctimas de forma más frecuente son los dolores físicos sin razón médica que los justifique. También se observan algunas cefaleas, fibromialgias y trastornos gastrointestinales, lo que implica un importante gasto para los sistemas de salud, especialmente si no se diagnostican ni tratan de forma adecuada. Son diversos los estudios que demuestran la frecuente presencia de trastornos de la conducta alimentaria en víctimas de abuso sexual infantil, especialmente de bulimia nerviosa. También se detectan trastornos de conversión, que incluyen la afectación de alguna de las funciones motoras o sensoriales de la víctima (APA, 2002). Las denominadas crisis convulsivas no epilépticas, que cambian brevemente el comportamiento de una persona y parecen crisis epilépticas, si bien no son causadas por cambios eléctricos anormales en el cerebro sino por la vivencia de acontecimientos fuertemente estresantes; y el trastorno de somatización, definido como la presencia de síntomas somáticos que requieren tratamiento médico y que no pueden explicarse totalmente por la presencia de una enfermedad conocida, ni por los efectos directos de una sustancia (APA, 2002).

Se ha observado, a su vez, la frecuente presencia de síntomas y trastornos disociativos en víctimas de abuso sexual infantil, referidos a aquellas situaciones en las que existe una alteración de las funciones integradoras de la conciencia, la identidad, la memoria y la percepción del entorno (http://pepsic.bvsalud. org/scielo.php?script=sci_arttext\&pid=S222090262012000100007: fecha de consulta: 6 de octubre de 2017). 


\subsubsection{Problemas sexuales}

Problemas de tipo sexual en víctimas de abuso sexual infantil, como una sexualidad insatisfactoria y disfuncional, conductas de riesgo sexual (como el mantenimiento de relaciones sexuales sin protección, un mayor número de parejas y una mayor presencia de enfermedades de transmisión sexual y de riesgo de VIH). Derivados de estos problemas de tipo sexual y, particularmente, de las conductas sexuales promiscuas y del precoz inicio a la sexualidad que presentan estas víctimas, destaca también la prostitución y la maternidad temprana.

La revictimización es una de las consecuencias del abuso sexual infantil relacionadas con el área de la sexualidad que supone una mayor gravedad. Por revictimización se entiende la experiencia posterior de violencia física y/o sexual en víctimas de abuso sexual infantil por agresores distintos al causante del abuso en la infancia (http://pepsic.bvsalud.org/scielo.php?script=sci_ arttext\&pid=S2220-90262012000100007: fecha de consulta: 6 de octubre de 2017).

\subsubsection{Embarazo}

Si bien este se plantea dentro de las últimas consecuencias como resultado de una violación, es una de la más graves que se está presentando en todo el mundo, la violación de niñas. Las cifras sobre los embarazos presentan la gravedad del problema y lo poco o nada que se ha planteado frente a este drama social. Guatemala, según reportes de OSAR y SOY 502, registra al menos 18,279 niñas de entre 10 y 19 años que han quedado embarazadas, siendo una realidad que se traduce a través de miles de historias de menores guatemaltecas, violadas por hombres usualmente mayores de edad. Existe un porcentaje alto de niñas embarazadas por violación de jóvenes, en donde además las jóvenes por ley no pueden decidir sobre sus vidas y de allí que los embarazos son considerados como violaciones sexuales cuando los jóvenes son menores de 14 años, aunque no exista violencia física o psicológica (página visitada: prensa libre/Guatemala/ comunitario/historias/ 18 noviembre 2017). 
En este aspecto cabe resaltar que Guatemala es uno de los países con tasas altas de fertilidad adolescente en donde las niñas menores de 14 años, que han sido víctimas de violencia sexual, han manifestado que sus perpetradores son familiares o cercanos a ellas, es por ello que este delito queda impune porque la situación es compleja cuando, como producto de la violación, se produce el embarazo.

Se dice que Guatemala es uno de los países con las tasas más altas de fertilidad adolescentes en Latinoamérica. En 2016 se registraron en el país 79 626 nacimientos de madres niñas y adolescentes, 2504 entre 10 y 14 años y 77 122 correspondientes a edades de 15 a 19 años (www.resumenlatinoamericano. org/2017/06/12/ la niñez de Guatemala sufre una violencia sexual que condiciona la vida de las jóvenes y sus hijos. Visitada el 18/11/2017).

En el año 2009 se reforma mediante Decreto número 09-2009, la Ley contra la Violencia Sexual, Explotación y Trata de Personas, el Código Penal en su artículo 173 relacionado a la violación, establece en su párrafo segundo que: "Siempre se comete este delito cuando la víctima sea una persona menor de catorce años de edad, o cuando sea una persona con incapacidad volitiva o cognitiva, aun cuando no medie violencia física o psicológica. Teniendo una pena de prisión de ocho a doce años".

\subsubsection{Transmisión intergeneracional}

La posible transmisión intergeneracional de las prácticas parentales, así como del maltrato y el abuso sexual infantil sigue siendo un tema de estudio controvertido y con resultados que pueden llegar a ser contradictorios. Un niño maltratado tiene alto riesgo de ser perpetrador de maltrato en la etapa adulta a su pareja o a sus hijos (http://pepsic.bvsalud.org/scielo.php?script=sci_ arttext\&pid=S2220-90262012000100007: fecha de consulta: 6 de octubre de 2017). 


\subsection{Derechos de las niñas víctimas}

\subsubsection{Derecho a la dignidad}

Toda víctima de un delito tiene derecho a que se le trate con justicia y respeto a su dignidad y a que se le preste atención integral e interdisciplinaria conforme sus necesidades.

\subsubsection{Acceso a la justicia}

El derecho de acceso a la justicia implica los derechos siguientes: a) Información y orientación jurídica: en esta materia la víctima de delito tiene los siguientes derechos: 1) A que el personal encargado de la recepción de denuncias sea especializado. La persona podrá presentar su denuncia o querella ante la Policía Nacional Civil, el Ministerio Público o los jueces del ramo penal, por escrito o verbalmente; en este último caso el funcionario redactará el acta correspondiente. Los menores de edad o de personas incapaces podrán presentar su denuncia o querella personalmente, y en estos casos, no se podrá negar la recepción de la denuncia invocando la carencia de representante legal. 2) Al momento de presentar la denuncia, que se le informe de sus derechos y de los mecanismos judiciales y administrativos aplicables a su caso. 3) A que el fiscal y/o juez competente le informe oportunamente sobre sus derechos, las pruebas requeridas y la trascendencia legal de cada una de las actuaciones, desde el inicio del proceso penal, así como sobre las medidas desjudicializadoras aplicables en el procedimiento penal del cual son parte. 4) A que el fiscal o funcionario que atienda la denuncia le oriente legalmente para el correcto ejercicio de la acción cuando se reclame la reparación del daño a los terceros obligados, y cuando proceda, en el ejercicio de la acción civil reparadora, en los términos establecidos por la ley. 5) A que el funcionario que reciba la denuncia le informe de su derecho a solicitar, a efecto de que el Ministerio Público le de asistencia letrada para el ejercicio de la acción civil, como lo establece el artículo 301 del Código Procesal Penal. El funcionario que reciba la denuncia consignará en el acta si informó con relación a este derecho y cuál fue la respuesta de la víctima. 6) A efectuar la diligencia de identificación del presunto responsable, en un lugar donde no puedan ser vistas por este, especialmente cuando se trate 
de delitos contra la libertad y la seguridad sexual y el pudor [reconocimiento personal]. 7) A que las instituciones involucradas en la administración de justicia respeten su derecho a comparecer a las audiencias, por sí o a través de sus representantes legales, para alegar lo que a su derecho convenga, en las mismas condiciones que el imputado. 8) A que las audiencias de juicios orales se celebren a puerta cerrada, con la presencia exclusiva de las personas que deben intervenir en ellas, en los casos de delitos contra la libertad y seguridad sexual y el pudor. 9) A impugnar por vía judicial la resolución del Ministerio Público que niega el ejercicio de la acción penal y el desistimiento de la misma, aun cuando la persona no se haya constituido como querellante adhesivo.10) A que el organismo jurisdiccional correspondiente notifique personalmente a la víctima de cualquier decisión, resolución o la práctica de cualquier audiencia que se produzca dentro del procedimiento penal. 11) A que el Ministerio Público la escuche previamente al realizar cualquier actuación o pretensión a adoptar en el proceso, y tome en cuenta sus opiniones e intereses dejando constancia de los motivos de cualquier decisión que tome cuando sea adversa a lo manifestado por la víctima, y a que comunique personalmente a la víctima tal decisión, así como cualquier resolución judicial dictada dentro del proceso. 12) A que el fiscal dé aviso al empleador de la víctima para que pueda ausentarse de su trabajo con goce de sueldo o salario, para que pueda comparecer las veces que sea necesario a prestar testimonio o a participar en cualquier diligencia relacionada con su proceso penal, sin que estas comparecencias sean causales de represalias o despidos injustificados. 13) A no ser expuesta innecesariamente ante el victimario durante el desarrollo del proceso penal para evitar su sobre victimización. Para tal efecto, el juez dispondrá de medidas especiales, para evitar la confrontación visual del imputado con la víctima, salvaguardando en todo caso el derecho de defensa. 14) A que el fiscal o el director del sistema penitenciario informe a la víctima sobre la condena, encarcelamiento, fuga o libertad del acusado, así como de cualquier resolución que ponga fin al proceso o sea relevante para la prosecución de la persecución penal. b) Protección frente a represalias: la víctima tiene derecho a solicitar que el fiscal y/o el juez competente promueva u ordene la aplicación de medidas de protección a su vida, integridad, domicilio, posesiones o derechos, cuando existan datos objetivos de que pudieran ser afectados por los presuntos responsables del delito o por terceros implicados. c) En cuanto a la presencia y participación en el proceso 
penal, la víctima tiene derecho: 1) A estar presente en todos los actos procesales en los cuales el inculpado tenga ese derecho. 2) A que el Ministerio Público diligencie o investigue toda la información que le proporcione la víctima, dejando constancia de su recepción y valoración. En caso de negativa la víctima tendrá derecho a acudir al juez de forma verbal o escrita. 3) A manifestar por sí o por su representante legal designado en el proceso, lo que a su derecho convenga.

\subsubsection{Derechos procesales}

La víctima del delito tendrá los siguientes derechos procesales: a) Derecho a la intimidad: la víctima de delito tiene el derecho a que se le trate con justicia y respeto a su intimidad durante todo el desarrollo del proceso penal. En el desarrollo de los exámenes practicados por médicos forenses, tiene derecho a estar acompañada por la persona de su elección o por un psicólogo, con el objeto de dar apoyo emocional y psicológico. b) Derecho a la privacidad: las víctimas tendrán derecho a que se les respete su vida privada y la de su familia.

a. Derecho de confidencialidad: las Directrices de Naciones Unidas sobre la Justicia en Asuntos Concernientes a los Niños Víctimas y Testigos de Delitos (aprobadas por el Consejo Económico y Social en 2005), reconocen el derecho a la protección de la intimidad de los niños y niñas víctimas y testigos de delitos como un asunto de primordial importancia y resaltan el deber de proteger toda la información relativa a la participación del niño o niña en el proceso de justicia, manteniendo siempre la confidencialidad y restringiendo la divulgación de cualquier información que permita su identificación. Asimismo, el derecho al respeto a la vida privada tratándose de niños, niñas o adolescentes acusados de haber cometido un delito, es también ampliamente recogido por la Convención sobre los Derechos del Niño y por las Reglas Mínimas de Naciones Unidas para la Administración de Justicia de Menores (aprobadas por la Asamblea General en 1985). El derecho de confidencialidad garantiza a la víctima el derecho a que no se publique o comunique sin su consentimiento en los medios impresos, radiales o televisivos 
en cualquier tiempo, los escritos, actas de acusación y demás piezas de los procesos, fotos, nombres de las víctimas o cualquier otro dato que pueda llevar a su individualización, contrarios a su dignidad, tal derecho también se reconoce en los artículos 152 y 153 de la Ley de Protección Integral de la Niñez y Adolescencia. El juez, a solicitud del fiscal, podrá ordenar que se prohíba la difusión de imágenes o noticias relacionadas con la víctima por cualquier medio de comunicación, cuando afecten su intimidad o causen daños a su reputación. Sin perjuicio de las responsabilidades penales correspondientes.

La instrucción general del Ministerio Público relacionada a la atención y persecución penal de delitos cometidos en contra de la niñez y adolescencia (instrucción 2-2013) indica como uno de los principios de estos procesos la confidencialidad y reserva, donde los fiscales no deben divulgar o proporcionar información a los medios de comunicación, a otros terceros sobre la identidad, domicilio y otros aspectos relacionados con la víctima y su familia, salvo cuando medie interés superior del niño, para lograr su localización. Cuando sea necesario los fiscales deben solicitar a los jueces y tribunales competentes la reserva penal y ordene al INACIF resguardar la información mencionada durante todas las fases del proceso penal.

b. Derecho a un Intérprete, traductor o asistencia: las instituciones involucradas en la atención de víctimas tienen a su cargo cuidar de que cuando la víctima no hable el idioma castellano o sea analfabeta, sorda, ciega o muda, cuente con un traductor, intérprete o persona que le asista en todas las actuaciones procesales.

c. Derecho de reparación digna, se entiende por reparación digna, restituir íntegramente a la persona sobre los daños y perjuicios que se le han ocasionado como consecuencia de un delito cometido en su contra. Se le denomina digna porque su reparación debe responder a la dignidad de esa persona. Sin embargo, a pesar de existir ese mecanismo protector hacia los agraviados y de estar contemplado su diligenciamiento en el ordenamiento procesal penal, aún persiste esa pérdida para ellos, a quienes no se les repara el daño causado de 
manera inmediata, sino deben acudir a ejecutarlo en la vía civil a realizar su reclamo correspondiente.

d. Las demás que señalen las leyes.

\subsubsection{Derecho de reparación del daño}

La víctima tiene derecho: a) A restitución por la persona condenada de la conducta penal que causó la pérdida o daño corporal de la víctima. b) A exigir del responsable del delito la restitución de la cosa, y si no fuere posible al pago de su valor a partir del momento de la perpetración del ilícito; esto con la aprobación del juez o fiscal, según corresponda. c) A la reparación del daño material y a la indemnización de los perjuicios del delito; a la reparación del daño moral. Si se trata de delitos contra la dignidad, a que a costa del responsable se publique la sentencia condenatoria en uno de los diarios de mayor circulación; esto cuando la víctima directa o colateral lo soliciten como una fórmula reparadora del daño moral. d) A exigir al Ministerio Público la realización de todos los medios de investigación necesarios para ejercitar la acción civil reparadora y que solicite medidas precautorias para hacer efectiva la reparación.

e. A exigir al Ministerio Público que recurra en apelación los autos que nieguen las medidas precautorias de embargo o restitución de derechos, así como la sentencia definitiva cuando no condene a la reparación del daño o imponga una cantidad inferior a la reclamada. f) A qué se le haga efectiva la garantía correspondiente a la reparación del daño en los casos que proceda. g) Las demás que señalen las leyes.

El Ministerio Público ha establecido en sus actuaciones conforme a la instrucción general 2-2013 que el fiscal durante la investigación y litigio debe orientar y solicitar a la víctima todos los elementos probatorios necesarios para acreditar el daño físico, psicológico y social y patrimonial y los tratamientos a seguir para obtener su completa y total reparación, los cuales deben incorporar al expediente.

En los procesos por delitos cometidos en contra de la niñez y adolescencia, el fiscal siempre solicitará la realización de la audiencia de reparación digna. 


\subsubsection{Derecho a la devolución de los bienes involucrados en el proceso penal}

Implica que se les devuelva de forma inmediata cualquier bien que les pertenezca, que hayan sido decomisados como evidencia. Solicitarán a la mayor brevedad los peritajes o reconocimientos que correspondan y, en su caso, se les entregue en calidad de depósito.

\subsubsection{Derecho a la asistencia médica}

En materia de atención médica, la víctima tiene derecho: a) A que se les proporcione gratuitamente atención médica-ictiológica con carácter prioritario en cualquiera de los hospitales nacionales de la República, cuando se trate de lesiones, enfermedades y trauma emocional provenientes del delito. b) A ser trasladada por cualquier persona al sitio apropiado para su atención médica, sin esperar la intervención de las autoridades. Quien preste este auxilio lo deberá comunicar de inmediato a la autoridad más cercana. c) A no ser explorada físicamente si no lo desea, quedando estrictamente prohibido cualquier acto de intimidación o fuerza física para este efecto. d) A que la exploración y atención médica (psiquiátrica, ginecológica o de cualquier tipo) cuando lo solicite, esté a cargo de facultativos de su mismo sexo y en presencia de un familiar o de quien represente un apoyo moral para ella. e) A ser atendida en su domicilio por facultativos particulares, independientemente del derecho de visita de los médicos forenses y la obligación de los médicos particulares de rendir y ratificar los informes respectivos. f) A contar con servicios victimológicos especializados, a fin de recibir gratuitamente tratamiento postraumático para la recuperación de su salud física y mental.

a. La víctima menor de edad no podrá ser objeto de exploración física bajo sedación, sin el consentimiento explícito de sus padres, tutores o guardadores, quienes deberán ser informados del propósito del procedimiento, el cual deberá ser totalmente indispensable y de gran interés para el desarrollo del proceso penal y no deberá conllevar peligro o riesgos para la vida o la integridad física y emocional de la víctima. h) Los demás que le otorguen las leyes. 


\subsubsection{Derecho a la atención y asistencia victimológica especializada por las Oficinas de Atención a la Víctima}

La víctima de delito tiene derecho a una atención especializada por las Oficinas de Atención a la Víctima del Ministerio Público en cualquier departamento de la República, por medio de sus médicos, trabajadores sociales, psicólogos y asesores legales especializados en materia de victimología. Asimismo, tendrá derecho a la atención por parte de las Oficinas de Atención a la Víctima de la Policía Nacional Civil y de la Procuraduría de los Derechos Humanos.

\subsection{Análisis de casos relacionados con niñas víctimas del delito de violación}

\subsubsection{Violación sexual}

Para muchas legislaciones, la violación está constituida por el acceso carnal con persona privada de sentido (razón), o empleando intimidación o fuerza; o bien cuando la víctima sea menor de 12 años por carecer de discernimiento para consentir el acto. En otras normativas, como la recién aprobada en Guatemala en el año 2009 que más allá del mero acceso carnal (penetración del miembro masculino), incluyendo la posibilidad de configurar este delito por la introducción, vía anal o vaginal, de uno o varios dedos u objetos, entre otros.

Una de las formas de violencia más común y denigrante dentro de la familia y fuera de ella, es la violencia sexual, que consiste en actos u omisiones que pueden ser desde negar las necesidades sexo-afectivas, hasta inducir a la realización de actividades sexuales no deseadas o a la violación. Los celos desmedidos y las acciones físicas o psicológicas que realizan para el control o manipulación de la pareja son una forma de violencia. La violencia sexual implica el uso de la fuerza física, la coerción o la intimidación psicológica para hacer que una persona lleve a cabo un acto sexual $\mathrm{u}$ otros comportamientos sexuales indeseados. Algunas de estas acciones serían: descalificación sobre la conducta sexual, obligar a tener relaciones sexuales sin consentimiento, obligar a protagonizar actos perversos, negar la sexualidad, estos actos buscan fundamentalmente someter el cuerpo y la voluntad de las personas. 
La violencia sexual tiene múltiples formas:

a. Acceso u hostigamiento en la calle, en el trabajo, en la casa, en el colegio, en la escuela, en la universidad, entre otros.

b. Violación.

c. Agresiones sexuales.

Tanto las mujeres como los hombres, niños, niñas y adolescentes son víctimas de abuso sexual. Las conductas vinculadas a la violencia sexual, se regulan en la legislación con las reformas introducidas al Código Penal, a través de la Ley Contra la Violencia Sexual, Explotación y Trata de Personas, Decreto número 9-2009 del Congreso de la República de Guatemala, y que vinieron a complementar el esfuerzo para eliminar la Violencia contra las Mujeres, Decreto número 22-2008 del Congreso de la República de Guatemala, Ley contra el Femicidio y Otras Formas de Violencia contra la Mujer.

La violencia sexual se define como: "Todo acto sexual, la tentativa de consumar un acto sexual, los comentarios o insinuaciones sexuales no deseados, o las acciones para comercializar o utilizar cualquier otro modo de sexualidad de una persona mediante coacción por otra persona, independientemente de la relación de esta con la víctima, en cualquier ámbito incluido el hogar y el lugar de trabajo".

La Ley de Protección Integral de la Niñez y la Adolescencia, prevé el derecho que tienen las niñas, niños y adolescentes a ser protegidos contra toda forma de explotación o abuso sexual, inclusive:

\section{i. La incitación o la coacción para que se dediquen a cualquier actividad sexual}

Al hablar de violación sexual se comprende que es el empleo de fuerza física que se dirige sobre el cuerpo o la voluntad del sujeto pasivo obligando a mantener relaciones sexuales. Las principales víctimas de este tipo de hechos son menores de edad, estos constituyen un grupo particularmente vulnerable y la mayoría de las violaciones posiblemente hasta ocho de cada diez casos 
ocurren en el seno del hogar y son perpetradas por familiares de la víctima, o por figuras de autoridad con quienes la familia tiene una relación de confianza como el pastor de una iglesia, un maestro o un cuidador.

Los delitos sexuales en el país constituyen el tipo de agresión donde casi el total de víctimas son mujeres. La condición de ser mujer en una sociedad que no supera aún raigambres de machismo, implica que la mujer se mantenga en condiciones de riesgo y ser objeto de abusos sexuales y demás hechos violentos relacionados al delito sexual. Los hechos de esta naturaleza son, en suma, un golpe a la dignidad e integridad como persona, con efectos negativos para el desarrollo de las mujeres y de la sociedad en su conjunto. La mayoría de mujeres víctimas de agresión sexuales aparentemente está comprendida entre la etapa de la pubertad y la adolescencia. Se ha reconocido la violencia sexual como uno de los asuntos humanitarios más preocupantes en Guatemala. Los sobrevivientes de violencia sexual se encuentran dentro de las poblaciones más vulnerables del país.

Los departamentos de Alta Verapaz, Huehuetenango, San Marcos, Quetzaltenango y Quiché exponen un índice de crecimiento en casos de violaciones sexuales, con base en las mediciones de la realidad social y económica del país demuestran que ser niña, pobre, indígena y residente en el área rural es garantía de estar colocada en el último lugar y la mayoría de veces el delito del cual son víctimas nunca se denuncie. Este se refleja al hacer mediciones sobre la cantidad menores de edad embarazadas, a todo esto, también se debe hacer énfasis en la discriminación racial, uno de los temas controversiales en este país, que a pesar de tener una ley contra la discriminación, los niveles de racismo son muy elevados e influye para que el delito de violación sexual sea cometido.

En el área rural y urbana se manifiesta el machismo al considerar a la mujer y las niñas, como personas de segunda clase, en ocasiones el hombre llega a la poligamia y siempre va en busca de una mujer más joven, por lo cual en muchas ocasiones no le es posible, y opta por relacionarse con mujeres de edad mayor que a su vez tienen hijas, que llenan sus expectativas siendo estas en ocasiones niñas, y al pertenecer al ambiente familiar, recurre a la violación sexual en contra de estas. 
La violación sexual se relaciona con la carencia de valores, hábitos y por costumbre. Dentro del ambiente familiar los mismos parientes de las jóvenes, niñas o niños son quienes les causan daño y la víctima guarda silencio por temor a represalias por parte del agresor. El temor es un problema particularmente recurrente cuando la víctima es menor de edad, cuando la agresión fue cometida por un familiar cercano, una pandilla o un individuo o grupo vinculado al crimen organizado y en las poblaciones pequeñas donde todos los vecinos se conocen y la víctima es más vulnerable a las represalias y a la estigmatización social.

La víctima en ocasiones calla por desconocimiento de sus derechos, temor a la discriminación, estigmatización social, amenazas y barreras sociolingüísticas en el caso de las mujeres indígenas, en otras ocasiones se enfrentan a limitaciones en el acceso a centros de asistencia. Además, los hombres que sufren una agresión sexual casi nunca denuncian; también podemos mencionar que cuando un menor de edad es agredido sexualmente por un familiar durante un período prolongado de tiempo, desarrolla un vínculo afectivo con el agresor, el llamado síndrome de Estocolmo, otro motivo por el cual guarda silencio y por estos factores que intervienen para que no se denuncie, es muy probable que las estadísticas oficiales sean conservadoras y no reflejen la magnitud del problema.

El fenómeno estudiado en la presente investigación es un cuadro perfecto de violencia contra la mujer en todos los sentidos que este artículo encierra. Las violaciones sexuales integran todos sus elementos y cabe resaltar que provocan serios daños psicológicos en las víctimas de este delito y estas pueden ser cometidas dentro del hogar por miembros de la familia o en la calle. El artículo dos dice: "Se entenderá que la violencia contra la mujer incluye la violencia física sexual y psicológica que tenga lugar dentro de la familia o unidad doméstica o en cualquier otra relación interpersonal, ya sea que el agresor comparta o haya compartido el mismo domicilio que la mujer y que comprende entre otros violación, maltrato y abuso sexual, que tenga lugar en la comunidad y sea perpetrada por cualquier persona y que comprende, entre otros, violación, abuso sexual, tortura, trata de personas, prostitución forzada, secuestro, y acoso sexual en el lugar de trabajo, así como instituciones educativas, establecimientos 
de salud y cualquier otro lugar, y que sea perpetrada o tolerada por el Estado o por sus agentes donde quiera que ocurra”.

Por su parte, el artículo cuatro afirma: "Toda mujer tiene el derecho al reconocimiento, goce, ejercicio y protección de todos los derechos humanos y a las libertades consagradas por los instrumentos regionales e internacionales sobre derechos humanos. Estos derechos comprenden entre otros: El derecho a que se respete su vida, el derecho a que se respete su integridad física, psíquica $y$ moral, el derecho a la libertad y a la seguridad personales, el derecho a no ser sometida a torturas, el derecho a que se respete la dignidad inherente a su persona y que se proteja a su familia, el derecho a la igual de protección ante la ley y de la ley, el derecho a un recurso sencillo y rápido ante los tribunales competentes, que la ampare contra actos que violen sus derechos, el derecho a que se respete la dignidad inherente a su persona y que se proteja a su familia".

El artículo tres expone: "Toda mujer tiene derecho a una vida libre de violencia tanto en el ámbito público como en el privado". Este derecho humano de las mujeres en Guatemala parece ir en retroceso cada día ya que la violencia como lo demuestran las estadísticas va en aumento no solo en los casos de violaciones sexuales, sino también en los de violencia intrafamiliar y asesinatos.

\subsection{Casos específicos}

De lo expuesto en los capítulos anteriores, se puede determinar por medio de los casos que se presentan, que la aplicación de la conciliación y el procedimiento abreviado entre otros, son mecanismos que reducen la dignidad de las niñas y mujeres y coartan su libertad e igualdad.

Para los efectos del análisis respectivo se presentan las situaciones y posición en que las niñas víctimas se ubican en el sistema judicial, conforme los procesos relacionados con un tipo penal de orden sexual. 


\subsubsection{Causa 01065-2014-00090 a cargo del Juzgado Segundo de adolescentes en Conflicto con la Ley Penal del departamento de Guatemala, seguida por el DELITO DE AGRESIÓN SEXUAL.}

En el presente expediente la víctima es una mujer adolescente de 14 años, condición económica de pobreza, ladina, y el adolescente agresor tiene 15 años, condición económica de pobreza, ladino.

En el referido proceso por agresión sexual, el Ministerio Público solicitó: "un criterio de oportunidad reglado dentro del presente proceso a favor del adolecente sindicado y su señor padre de cancelar la cantidad de dos mil quetzales a la parte agraviada consistente en diez sesiones de terapia de psicología entregando recibo, aunado a que es un delito en donde no se vio afectado el interés público ni la seguridad ciudadana y que la juzgadora aplique Reglas de la Abstención que considere pertinentes..." y resolvió: “Con lugar el Criterio de oportunidad reglado a favor del adolescente, solicitado por el Ministerio Público, por las razones ya consideradas. Se hace constar que el adolescente sindicado y su señor padre cancelaron la cantidad de dos mil quetzales a la parte agraviada consistente en diez sesiones de terapia psicológica, los cuales fueron entregados a la profesional en Psicología entregando recibo correspondiente. Se archiva por el plazo de un año." (La negrilla y subrayado es propio). El argumento utilizado por la juzgadora y el fiscal es contrario al principio de interés superior del niño, -en el presente de la niña víctimapues este debe anteponerse y prevalecer ante "el interés público y la seguridad ciudadana". Además, no advirtió que, por tratarse del delito de agresión sexual, es un delito grave, por lo que la conciliación no era aplicable, ello en atención a lo previsto en el artículo 185 de la Ley de Protección Integral de la Niñez y Adolescencia.

Dicho delito deja secuelas irreparables para la víctima, las cuales no desaparecerán con diez terapias psicológicas. Evidenciando que no se tomó en cuenta que la víctima es una mujer menor de edad, beneficiando con ello al trasgresor de la ley penal, (que también es un menor de edad) a que por este beneficio pueda obtener su libertad y con la posibilidad de que pueda volver a 
cometer un ilícito mayor en perjuicio de las mujeres y las niñas. En el presente caso se puede observar que tanto el Ministerio Público como la juzgadora desconocieron el marco internacional específico de protección para las mujeres y las niñas, y la Convención de los Derechos del Niño, sobreponiendo el interés superior del joven agresor frente al interés superior de la adolescente víctima, a la libertad, integridad, dignidad y a vivir una vida libre de violencia, olvidando que la agresión sexual es un hecho denigrante en contra de la dignidad e integridad de toda persona.

\subsubsection{Causa 01065-2015-00027 a cargo de. Juzgado Segundo de Adolescentes en Conflicto con la Ley Penal del departamento de Guatemala, seguida por el DELITO DE AGRESIÓN SEXUAL.}

En el referido proceso, el Ministerio Público solicitó, "que se deje sin efecto el memorial de acusación y solicitud de apertura a juicio en contra del adolescente (...) y que se aplique un criterio de oportunidad reglado dentro del presente proceso, ya que no se ubicó a la parte agraviada y en beneficio de ambas partes, que dicho adolescente continúe estudiando y que se le apliquen las reglas de abstención que se consideren pertinentes... y resolvió: por el interés superior del adolescente, el hecho no se consumó y a la otra parte agraviada no se le ubica como corresponde, se declara con lugar el criterio de oportunidad reglado a favor del adolescente (...), solicitado por el Ministerio Público y el abogado defensor, por las razones y a consideradas. Se archiva por el plazo de un año".

En esta resolución es flagrante la vulneración del derecho de defensa y debido proceso que le asiste a la víctima, del principio jurídico de interés superior, pues no solo la audiencia no debió llevarse a cabo sin presencia de la víctima, pues ello es contrario a lo previsto en el artículo 188 de la Ley de Protección Integral de la Niñez y Adolescencia que dispone que: “Audiencia de conciliación. Para realizar la audiencia conciliatoria se citará al adolescente, a su representante legal o persona responsable, a la parte ofendida o víctima, que, si fuere adolescente, la citación comprenderá además a su representante legal. Se citará además al defensor y al fiscal, cuando ya hubieran tenido participación en el proceso. Si alguna de las partes indispensables dejase de concurrir a la audiencia 
de conciliación, se dejará constancia de ello y se continuará el procedimiento. Lo anterior no impedirá que pueda realizarse una nueva audiencia de conciliación” (el resaltado es propio). Sino, además, que con esta medida el único beneficiado es el agresor, al evitar el proceso seguido en su contra y que se cumplan con los fines del proceso penal, especialmente la averiguación de la verdad y la reparación del daño causado a la víctima, según corresponda. Asimismo, se observa, que no se toma en cuenta, que la víctima es mujer menor de edad, evidenciando la discriminación por razón de género, pues se favorece al varón trasgresor de la ley penal.

\subsubsection{Causa 01065-2016-00050 a cargo del Juzgado Segundo de Adolescentes en Conflicto con la Ley Penal del departamento de Guatemala, por el DELITO DE VIOLACIÓN.}

En el presente caso se conoció que la mujer víctima de violación es una niña de 13 años, ladina de condición económica de pobreza, y el hombre adolescente victimario cuenta con 17 años, ladino de condición económica de pobreza.

Ante la solicitud efectuada por el Ministerio Público, la juez de la causa resolvió: "I. Con lugar los requerimientos efectuados en la presente audiencia por el Ministerio Público. II. En la forma solicitada y de acuerdo a las argumentaciones sustentadas por el representante del Ministerio Público se aprueba que se prescinda de la persecución penal en el presente proceso; por las razones consideradas; III. En consecuencia se otorga el beneficio del criterio de oportunidad reglado a favor del adolescente (...). IV. Se imponen Reglas: A. continúe con sus estudios y B Asistir a terapia psicológica en orientación sexual. $V$. Al estar firme la presente resolución, archívese el proceso respectivo con lo cual se tendrá por extinguida la acción penal”; d) causa 01065-201600042 a cargo del Juzgado Segundo de Adolescentes en Conflicto con la Ley Penal del departamento de Guatemala, los sujetos procesales solicitaron: "Ministerio Público: Solicita un criterio de oportunidad reglado dentro del presente proceso a favor del adolescente sindicado (...), toda vez que no afectó gravemente el interés público, no se vio afectada la seguridad ciudadana, con el objeto de que el mismo se reintegre a la sociedad, que se prescinda de la persecución penal, que continúe asistiendo a SODEJU para recibir terapia psicológica, que continúe 
residiendo en la misma casa con la supervisión de sus señores padres, que continúe sus estudios y que los padres del sindicado en representación de dicho adolescente cancelen a la parte agraviada la cantidad de ocho mil quetzales para terapias psicológicas..." y resolvió: "Este Juzgado con fundamento en lo considerado, leyes citadas y constancias en autos, DECLARA: I. Con lugar el criterio de oportunidad reglado a favor del adolescente (...) solicitado por el Ministerio Público.

Una vez más, se observa que el criterio del juzgador, es errado ya que al tenor del artículo 185 de la Ley de Protección Integral de la Niñez y Adolescencia, no procede la conciliación, pues es un delito grave, se evidencia que con una medida de esta naturaleza, al único que se beneficia es al adolecente trasgresor de la ley penal. Se desvaloriza a la niña víctima pues con una cantidad de dinero se pretende subsanar el daño causado, como lo es la violación, el cual genera un daño irreparable en la vida de todo ser humano. No obstante, la juez no interpretó de forma correcta las disposiciones internaciones en materia de niñez y adolescencia, los principios rectores que protegen a łas niñas víctimas de delitos, así como disposiciones internas que buscan que en estos hechos judicializados se respete a la víctima, más aún por su condición de niña. Esto agrava la situación porque no reciben tratamiento, ni protección ni justicia, dando como resultado incumplimiento de la debida diligencia.

\subsubsection{Causa 01065-2015-00041 a cargo del Juzgado Segundo de Adolescentes en Conflicto con la Ley Penal del departamento de Guatemala, por el delito DE AGRESIÓN SEXUAL, en audiencia de procedimiento abreviado.}

En el presente caso es una mujer víctima de 8 años, ladina, de condición económica de pobreza, y un adolescente agresor de 15 años ladino de condición económica de pobreza.

El presente caso se llevó cabo en audiencia de procedimiento abreviado en donde el Ministerio Público solicitó en memorial de acusación y apertura a juicio que se le aplicara criterio de oportunidad reglado en beneficio de ambas partes, siendo así que el adolescente agresor continúe estudiando, que aprenda 
un oficio y reciba terapia psicológica y que le entregue a la parte agraviada la cantidad de ocho mil quetzales convenida con anterioridad para la terapia psicológica de la niña víctima.

Observándose que es reiterada la inobservancia de aplicar el marco internacional de protección y de respetar lo establecido por la legislación especializada, autorizando peticiones que están al margen de lo que le establece la ley en la materia.

En este caso la juzgadora manifiesta que se resuelve por el interés superior de ambas partes, esto no es razonable ya que la víctima notoriamente queda en total desprotección en donde se envía una lectura de que las agresiones sexuales son permisibles cuando se es hombre adolescente, en donde únicamente se le requiere atender un oficio, y recibir terapias, lo que resulta totalmente alejado de la realidad y con ello se refuerza a que el número de niñas víctimas sigan siendo sujetas de vejámenes como los presentes porque existe una cultura de indiferencia y de negar que estas formas de violaciones a derechos humanos para las mujeres, van en detrimento de la persona humana y por ende de la sociedad, por lo que plantear que no afecta gravemente el interés público ni la seguridad ciudadana es atender dichos preceptos de manera limitada, no observando la dinámica social, y el alcance jurídico y axiológico que abarca el interés público y la seguridad ciudadana.

Con los casos antes enunciados, queda evidenciado que las resoluciones dictadas dentro de los procedimientos de adolescentes en conflicto con la ley penal, han sido dictadas, vulnerando los derechos fundamentales de las niñas víctimas, en los hechos considerados como violencia sexual, lo que pone de manifiesto la necesidad de que estos sean erradicados para contribuir a la equidad de género, claro está, en aquellos casos en que se invoque la conciliación.

De lo anterior podemos concluir, que debe revisarse la situación de la niñez y adolescencia víctima en relación con los adolescentes en conflicto con la ley penal, específicamente en los delitos de violencia sexual, cuando se solicite aplicar un criterio de oportunidad, específicamente la conciliación y el procedimiento abreviado, siendo obligatorio atender de manera integral la 
legislación especializada en materia de derechos humanos de la niñez y de las mujeres, y no considerar a una de estas partes como derechos absolutos.

Es importante evidenciar que en estas sentencias donde se aplican estas formas desjudicializadas, el Estado asume la responsabilidad solidariamente por acción u omisión cuando sus funcionarios o funcionarias públicas, que obstaculicen, retarden o nieguen el cumplimiento de las sanciones previstas en las normativas con observancia en las convenciones sobre derechos humanos, ya que las mismas reflejan, además, una carga estereotipada al considerar que no se cometió invocando que es un delito en donde no se vio afectado el interés público ni la seguridad ciudadana, invisibilizando los efectos que para la otra parte-niña víctima- repercutirá en su vida, vulnerando con ello sus derechos humanos. 


\section{CONCLUSIONES}

I. La Constitución Política de la República de Guatemala establece como régimen especial de tutela, el sistema de protección de los niños, niñas y adolescentes, y el principio de interés superior del niño, que se encuentra consagrado en la Convención de los Derechos del Niño y demás leyes del ordenamiento jurídico como consideración primordial, que deben atender los tribunales de justicia en sus resoluciones judiciales.

II. En procesos penales donde los niños y niñas y/o adolescentes intervienen se evidencia la colisión del principio de interés superior del niño, frente a otros principios y garantías constitucionales y procesales. En estos casos, debe utilizarse el método ponderativo por medio de las máximas de la proporcionalidad, necesidad y adecuación en aras de que se proteja la justicia, la tutela judicial efectiva y el principio de interés superior del niño, consagrados en la Constitución Política de la República de Guatemala y en la Convención sobre los Derechos del Niño comprendiendo que este no es un derecho absoluto ya que se encuentra la justicia frente a dos sujetos que por razón de la edad, deben ser protegidos, aplicando el principio de la igualdad con equidad, ya que la niña víctima no obtiene una justicia de manera adecuada y oportuna, dándose con ello el incumplimiento en la debida diligencia para investigar, sancionar y reparar un acto de violencia contra las mujeres.

III. Deviene improcedente la aplicación de la conciliación y del procedimiento abreviado cuando se trate de delitos graves, no obstante, varios juzgadores de primera instancia de adolescentes en conflicto con la ley penal, aplican el mismo, pero en forma errónea, ya sea por desconocimiento de derechos humanos y con cargas estereotipadas atienden estos procedimientos en los cuales es notorio que se ha cometido delito grave en contra de las niñas víctimas, contrariando de esta manera lo previsto en el artículo 185 de la Ley de Protección Integral de la Niñez y Adolescencia, pero especialmente de las Convenciones Internacionales en materia de Derechos Humanos, como lo es la Convención para Eliminación de Todas las Formas de Discriminación contra la Mujer en sus siglas "Cedaw", la Convención Interamericana para Prevenir, Sancionar y Erradicar la Violencia contra la Mujer "Belém Do Pará" y la Convención sobre los Derechos del Niño. 
IV. Desde la teoría de género, tomando en cuenta la existencia de sistemas en los que se expresan relaciones de poder o de abuso de poder, que algunas sociedades elaboran a partir de la diferencia sexual, se caracteriza por el uso de mecanismos y técnicas para el control de las capacidades femeninas especialmente en las niñas víctimas, que si bien tienen derecho a opinar sobre asuntos que les competen, también lo es que en una conciliación entre víctima y victimario en términos de igualdad y favorecida por el sistema de justicia, no es lo más recomendable para la niña víctima (no obstante que los padres, tutores o cualquier otro representante legal de la misma se encuentre presente en la audiencia de conciliación de mérito. Y, tomando en consideración que la mencionada audiencia de conciliación lo que trata primordialmente es que la parte activa del delito dé cierta cantidad de dinero a la parte pasiva, la cual realmente sirve para pagar una atención mínima psicológica a un profesional, la cual no es integral y con ello se estaría equiparando la indemnización como un sustituto de la persecución penal, sin tomar en cuenta todos los aspectos que afectan a las víctimas, en este caso se observa que lo que implica ser una niña - mujer, en un país donde el Estado refuerza la cultura patriarcal que estimula a los hombres agresores a seguir formas de violencia sexual como permisibles, fortaleciendo con ello altos índices de impunidad en el sistema de justicia al atender la violencia contra las mujeres y las niñas se aplican dicotómicamente procedimientos judiciales para este tipo de ilícitos, lo cual repercute en las niñas.

V. Con la conciliación se privilegia al menor trasgresor de la ley penal, pues se le beneficia en que puede logar su libertad por mecanismos en los cuales se retuerce la ley, tanto por juzgadores, fiscales y defensores, impactando de esa manera en la sociedad, pues no dictan sus resoluciones atendiendo desde una perspectiva de género y tomando en consideración, específicamente, que la víctima sea mujer menor de edad.

VI. De la conclusión planteada, la hipótesis expresada en el Plan de trabajo ha sido confirmada ya que se demostró en el desarrollo de la investigación que la conciliación y el procedimiento abreviado, al ser aplicados en los delitos de violencia sexual, en donde no proceden, constituyen una violación los derechos fundamentales de las niñas víctimas de violencia sexual, no observando el marco convencional existente. 


\section{BIBLIOGRAFÍA}

Asociación Argentina de Prevención del Maltrato Infanto-Juvenil. -Asapmi-Zuccolillo, Marisa (2017). "El interés superior del niño" en la Convención sobre los Derechos del Niño y otras Leyes. Argentina. Editorial Albremática. Recuperado de http:// www.asapmi.org.ar/publicaciones/articulos-juridicos/?id=520.

Carbonell Miguel (Coordinador) (2011). Argumentación jurídica, el juicio de ponderación y el principio de proporcionalidad. México.

CICAM. Proyecto reducción de la violencia contra la mujer (2002). Propuesta de Ley para Reformar el Código Procesal Penal. Guatemala.

Código de Menores (1979). Congreso de la República de Guatemala, Decreto 78-79.

Código de la Niñez y la Juventud (1996). Congreso de la República de Guatemala, Decreto 78-96.

Código Penal (1973). Congreso de la República, Decreto número 17-73.

Código Procesal Penal (1992). Congreso de la República, Decreto número 51-92.

Constitución Política de la República de Guatemala (1986). Asamblea Nacional Constituyente.

Corte de Constitucionalidad. (2000). Expediente 368-2000. Sentencia del diecisiete de agosto de 2000 .

Corte de Constitucionalidad. (2007). Expediente 1527-2006. Sentencia de seis de noviembre de 2007

Corte de Constitucionalidad. (2009). Expediente 3690-2009. Sentencia del cuatro de de octubre de 2009.

Corte de Constitucionalidad. (2012). Expediente 1822-2011. Sentencia de diecisiete de julio de 2012.

Convención Americana sobre Derechos Humanos "Pacto de San José". (1948). Declaración Universal de Derechos Humanos. Adoptada y proclamada por la Asamblea General en su resolución 217 A (III) el 10 de diciembre de 1948.

Federación Iberoamericana del Ombudsman. (2015). Debida diligencia en el acceso a la justicia y tutela judicial efectiva de las mujeres víctimas de la violencia familiar: alcances, limitaciones y propuestas. Guatemala.

Grupo Multidisciplinario para la defensa de los derechos sexuales y reproductivos. (2013) Estereotipos sexistas en sentencias relacionadas con delitos de violencia sexual. Guatemala. 
Ley del Organismo Judicial. (1989). Congreso de la República de Guatemala, Decreto 2-89,

Ley Orgánica del Ministerio Público. (1994). Congreso de la República de Guatemala, Decreto 40-94.

Ley contra la Violencia Sexual, Explotación y Trata de Personas. (2009). Decreto 9-2009 Congreso de la República.

Ley para Prevenir, Sancionar y Erradicar la Violencia Intrafamiliar. (1996) Congreso de la República, Decreto número 97-96, 1996.

Ley de Protección Integral de la Niñez y la Adolescencia. (2003). Congreso de la República, Decreto número 27-2003.

Ley para Prevenir, Sancionar y Erradicarla Violencia Intrafamiliar. (1996). Congreso de la República de Guatemala, Decreto 97-96.

Mejer Julio (1991). La víctima y el sistema penal, en jueces para la democracia. España: (s.e.).

Ministerio Público. (2014). Compendio de acuerdos e instrucciones sobre atención victimológica. Guatemala.

Ministerio Público. (2015). Derechos Humanos de la Niñez y Adolescencia. Tomo 3. Guatemala.

Ministerio Público. (2015). Derechos Humanos de las mujeres. Tomo 2. Guatemala.

Ministerio Público. (2015). Derechos humanos y derechos de las víctimas. Tomo 1. Guatemala.

Naciones Unidas. Convención Americana de Derechos Humanos

Naciones Unidas. (1959) Declaración de los derechos del Niño.

Naciones Unidas. (1985) Declaración de las Naciones Unidas sobre los Principios Fundamentales de Justicia relativos a las Víctimas de Delitos y del Abuso de Poder. Asamblea General de las Naciones Unidas.

Naciones Unidas. (1979). Convención sobre la Eliminación de todas las Formas de Discriminación contra la mujer-CEDAW-.

Naciones Unidas. (1994). Convención Interamericana para Prevenir Sancionar y Erradicar la Violencia contra la Mujer, Convención de Belém do Pará.

Naciones Unidas. (1999). Protocolo Facultativo de la CEDAW, Protocolo Facultativo de la Convención sobre la Eliminación de Todas las Formas de Discriminación contra la Mujer. Adoptada por la Asamblea General en su resolución A/54/4 de 6 de octubre de 1999. Ratificado el 30 de abril del año 2002. 
Organización de las Naciones Unidas para la Educación, la Ciencia y la Cultura. (2017) Derecho a la Educación. Recuperado de: http://www.unesco.org/new/es/ education/themes/leading-the-international-agenda/right-to-education/.

Organismo Judicial. (2011). Marco Normativo Nacional en materia de violencia contra la mujer. Guatemala.

Recomendación número 19 del Comité para la Eliminación de la Discriminación contra la Mujer. Oficina del Alto Comisionado de las Naciones Unidas para los Derechos Humanos.

Asamblea General de las Naciones Unidas. (1985). Reglas mínimas de las Naciones Unidas para la administración de la justicia de menores (reglas de Beijing). Resolución 40/33, 1985.

Rodríguez Barillas, Alejandro. (2002). Los derechos de la niñez víctima en el proceso penal guatemalteco (s.e.) Publicado por UNICEF. Guatemala. 2002

Rodríguez Barillas, Alejandro. (2007). Sistema penal y víctima. Una propuesta de atención integral desde el apoyo comunitario. Guatemala.

Salinas Beristaín, Laura. (2002). Derecho, género e infancia. Mujeres, niños, niñas y adolescentes en los códigos penales de América Latina y el Caribe hispano. Colombia.

Suprema Corte de Justicia de la Nación, Instituto de Investigaciones Jurídicas de la Universidad Autónoma de México. (2016). Impartición de justicia con perspectiva de género. México.

UNICEF. (2001). Organismo Judicial. Modulo sobre los Derechos del Niño en Guatemala.

Kronawetter, A. (1997). La víctima en el proceso penal, su régimen legal en Argentina, Bolivia, Brasil, Chile, Paraguay, Uruguay. De Palma, Buenos Aires: (s.e.). 
Opus Magna Constitucional

Corte de Constitucionalidad - Instituto de Justicia Constitucional

ISSN: 2707-9856 - opusmagna.cc.gob.gt • Guatemala • Tomo XVI • abril 2019 - marzo 2020 